\title{
CARL SCHMITTS „GROSSRAUMLEHRE” IM KONTEXT DES NATIONALSOZIALISMUS
}

\section{CARL SCHMITT'S THEORY OF “GROSSRAUM" IN CONTEXT OF NATIONALSOCIALISM}

\author{
Peter Techet \\ Albert-Ludwigs-Universität Freiburg
}

\begin{abstract}
SUMARIO: EINFÜHRUNG; I. GROSSRAUMLEHRE ALS ALTERNATIVE ZUM „WELTRECHT“ UND ZUR SOUVERÄNEN STAATLICHKEIT: 1. 1. Großraum als politische Einheit: Primat des Politischen, 1. 2. Großraum als postvölkerrechtliche Einheit: Gegen ein Weltrecht, 1. 3. Großraum als partikulare Einheit: Für ein raumbezogenes Völkerrecht, 1. 4. Großraum als post-staatliche Einheit: Gegen staatliche Souveränität; 1. 5. Großraum als hegemoniale Einheit: Für das Reich; II. GROSSRAUMLEHRE ALS NATIONALSOZIALISTISCHE LEHRE: 2. 1. Großraum und Volk, 2. 2. Großraum und Reich, 2. 3. Schmitts Großraumlehre als NS-Lehre?; AUSBLICK: WER SOLL NOCH SCHMITT LESEN?
\end{abstract}

Resumen: Los debates sobre cómo Europa puede organizarse como una unidad tuvieron lugar también en la Alemania nacionalsocialista. El objetivo en ese momento era unir Europa bajo la hegemonía alemana, como un "gran espacio" alrededor de un imperio alemán. Carl Schmitt proporcionó con su "Großraumlehre" una de las teorías más conocidas de una Europa nacionalsocialista. Carl Schmitt desarrolló su teoría contra la posibilidad de un "derecho mundial" y contra la soberanía estatal. En este trabajo, el "Großraumlehre" será analizada, por un lado, en el contexto de la doctrina jurídica anti-universalista y anti-pluralista como alternativa a la doctrina juridica universalista y pluralista de Hans Kelsen. (I.) Por otro lado, la teoría de Schmitt estará ligada a otros planes europeos nacionalsocialistas claramente racistas. (II.) Al final de este artículo, también abordo la cuestión de si y por qué la teoria de Schmitt, a pesar del contexto en el que surgió, podria seguir siendo compatible con los debates actuales sobre Europa y la politica global. (Ausblick)

Abstract: The debates on how Europe can be organized as a unity took place in the National Socialist Germany too. The aim at that time was to unite Europe under German hegemony - as a "large space" around a German empire. Carl Schmitt provided with his "Großraumlehre" one of the best-known theories of a National Socialist Europe. Carl Schmitt developed his theory against the possibility of "world law" as well against state sovereignty. In this paper, the "Großraumlehre" will be analysed, on the one hand, in the context of Schmitt's anti-universalistic and anti-pluralistic legal theory as an alternative to the universalistic and pluralistic legal theory of Hans Kelsen. (I.) On the other hand, Schmitt's theory will be linked to other - clearly racist - National Socialist European plans. (II.) At the end of this paper, I also address the question of whether and why Schmitt's theory - despite the context in which it came out could remain compatible with today's debates on Europe and global politics. (Ausblick) 
Palabras clave: derecho internacional; Carl Schmitt; Hans Kelsen; Otto Koellreutter; Nacionalsocialismo; "Großraumlehre"; historia del derecho; teoria del derecho; Alemania; nomos; antisemitismo, racismo

Key Words: International Law; Carl Schmitt; Hans Kelsen; Otto Koellreutter; National Socialism; "Großraumlehre"; History of Law; Theory of Law; Germany; Nomos; Antisemitism; Racism

\section{EINFÜHRUNG}

Der Gedanke, dass Europa eine politische Einheit bilden solle, taucht immer wieder in der europäischen Ideengeschichte auf. Die heutigen Debatten über die politische Zukunft des Kontinents - und überhaupt darüber, wo und wie sich Europa begreifen lässt - wurden auch während des zweiten Weltkrieges geführt, als eine Macht vorhatte, Europa zu „einigen". ${ }^{1}$ Es geht um das nationalsozialistische Deutschland. Das NS-Regime vertrat aber keine ausgeprägten Ideen über die Zukunft Europas - noch weniger kann und darf der Nationalsozialismus als eine europafreundliche Strömung bezeichnet werden. ${ }^{2}$ Die NS-Propagandisten und die führenden Politiker der NSDAP verfolgten dabei eine imperialistisch-rassistische Kriegspolitik. Die damaligen Diskurse zeigen allerdings pars pro toto, dass und wie eine "europäische“ "Einheit" nicht nur pazifistisch und liberal - wie im europäischen Einigungsprozess seit 1957 -, sondern auch faschistisch-kriegerisch gedacht werden kann. ${ }^{3}$

Im folgenden Aufsatz steht die Schmittsche Großraumlehre im Vordergrund. Sie lässt sich als ein dialektischer Versuch begreifen, das universalistische „Weltrecht" durch Kritik an der souveränen Staatlichkeit zu verhindern: Schmitts Lehre richtete sich gleichzeitig gegen ein universalistisches "Weltrecht" und die Aufrechterhaltung einer staatlich gespaltenen Weltordnung. (I.) Es werden auch andere NS-Theorien bezüglich der Neuorganisation Europas kursorisch mit betrachtet, damit der Kontext erfasst werden kann, in dem Schmitts Großraumlehre entstand. (II.) Obwohl sich die Schmittsche Großraumlehre in

$1 \mathrm{Zu}$ diesen Plänen siehe u.a. Paul Kluke, „Nationalsozialistische Europaideologie”, Vierteljahrshefte für Zeitgeschichte, 3, 1955/3, pp. 240-275.; Yves Durand, Le nouvel ordre européen nazi. La collaboration dans l'Europe allemand 1938-1945, Complexe, Bruxelles, 1990; Jörg K. Hoensch, „Nationalsozialistische Europapläne im zweiten Weltkrieg”, in: Richard G. Plaschka et al (Hg.), Mitteleuropa-Konzeptionen in der ersten Hälfte des 20. Jahrhunderts, Verlag der ÖAW, Wien, 1995, pp. 307-325.; Christian Joerges / Navraj Singh Ghaleigh (Hg.), Darker Legacies of Law in Europe. The Shadow of National Socialism and Fascism over Europe and its Legal Traditions, Hart, Oxford / Portland, 2003; Paolo Fonzi, „Nazionalsocialismo e Nuovo ordine europeo: La discussione sulla "Großraumwirtschaft"”, Studi Storici, 45, 2004/2, pp. 313-365.; Johannes Daffinger / Dieter Pohl (Hg.), A New Nationalist Europe Under Hitler. Concepts of Europe and Transnational Networks in the National Socialist Sphere of Influence, 1933-1945, London, 2020.

2 Michael Salowski, „Europa: Idee und Wirklichkeit in der nationalsozialistischen Weltanschauung und politischen Praxis", in Otmar Franz (Hg.), Europas Mitte, Muster-Schmidt, Göttingen / Zürich, 1987, p. 88.

3 Daher kann sich die nationalistische EU-Kritik als Antifaschismus und Antiimperialismus inszenieren, als Beispiel dazu siehe u.a. Thierry Baudet, „Juist Europese eenwording leidt tot oorlog", NRC Handelsblad, 23. 06. 2012, p. 4. 
vielen Punkten mit den Zielen des Hitler-Regimes übereinstimmte, fehlte ihr ein explizit biopolitisches Element. Deswegen wird am Ende kurz aufgezeigt, ob und wie sie an die heutigen völkerrechtlichen und weltpolitischen Debatten anschlussfähig bleibt. (Ausblick)

\section{GROSSRAUMLEHRE ALS ALTERNATIVE ZUM „WELTRECHT“ UND ZUR SOUVERÄNEN STAATLICHKEIT}

Nach seinem Rückzug aus der Öffentlichkeit 1936 befasste sich Carl Schmitt immer intensiver mit völkerrechtlichen Themen. Seine Völkerrechtslehre bettete sich allerdings sowohl in seine früheren Theorien als auch in die damaligen NSDiskurse ein. Schmitt bemerkte den Verfall der Staatlichkeit bereits in der Weimarer Republik, deswegen nahm er sich des Politischen und nicht der Staatlichkeit an. In der Weimarer Republik sah er die Staatlichkeit durch die pluralistische Demokratie bedroht, deren Interessengruppen und Parteien sich des Staates bemächtigt hätten. Deswegen begrüßte er die nationalsozialistische Wende als Beseitigung des Pluralismus - allerdings bedeutete diese auch einen anti-etatistischen Wendepunkt, weil der Nationalsozialismus (zumindest nach seiner Ideologie) das Volk als neue politische Kategorie in den Vordergrund stellte. Nach der NS-Machtübernahme wurde die pluralistische Demokratie in Deutschland - im Sinne von Carl Schmitt - beseitigt, das neue Regime wandte sich außenpolitischen Zielen zu. Durch die NS-Außenpolitik fand der 1936 in einer SS-Zeitschrift angegriffene Schmitt wieder Anschluss an das Regime: So wie er mit seinen Weimarer Schriften den Weg in den Nationalsozialismus geebnet hatte, untermauerte er mit seiner Großraumlehre die NS-Kriegspolitik.

Für Schmitts völkerrechtliches Interesse waren die weltpolitischen Veränderungen bedeutend, die er als Ende der Staatlichkeit - als einer in der europäischen Frühneuzeit entstandenen politischen Form der Weltordnung wahrnahm. Einerseits befürchtete er eine einheitliche Weltordnung, in welcher die antagonistischen Gegensätze - die seinem Begriff des Politischen zugrunde lagen - verschwinden würden; andererseits meinte er, dass die souveräne Staatlichkeit gegenüber den universalistischen Tendenzen des neuen Völkerrechts an Kraft und Bedeutung verloren hätte. In seiner Völkerrechtslehre entwickelte er eine neue Kategorie, welche das Primat des Politischen (1.1.) durch Verhinderung einer universalistischen Rechtsordnung (1.2.) aufrechterhalten könne; Schmitts Großraumlehre folgt aus seiner anti-universalistischen Rechtslehre. (1.3.) Die neue Kategorie vom Großraum bedeutete allerding auch die Überwindung der souveränen Staatlichkeit (1.4.), die Schmitt nicht mehr als die maßgebende politische Einheit für ein planetarisch gewordenes Völkerrecht erachtete. Schmitt schrieb die „Aufgabe“, die Welt politisch zu gestalten bzw. innenpolitisch den Pluralismus zu beseitigen, dem „Reich“ - als einer poststaatlichen politischen Einheit - zu. (1.5.)

In den folgenden Unterkapiteln wird der Großraum in diesen angedeuteten Aufgaben und Eigenschaften beschrieben - zugleich mit Hans Kelsens Völkerrechtsverständnis kontrastiert. 


\section{1. Großraum als politische Einheit: Primat des Politischen}

Schmitt war überzeugt, dass die Weltordnung nur dann politisch bleiben könne, wenn sie keine Einheit bilde. Er war ein entschiedener Gegner einer universalistischen Weltordnung, er verstand eine universalistische Welt einerseits als Ende des Politischen - das Politische benötige nämlich antagonistische Gegensätze -; andererseits lehnte er jegliche Universalismen ab, weil er jedes Phänomen (wie das Recht selbst) als historisch gewachsene, volks- und raumgebundene, partikulare Erscheinung interpretierte. Der Universalismus war für ihn bloß die Verschleierung gewisser partikularen Interessen. Schmitt meinte, dass der von ihm prognostizierte Abgang der Staatlichkeit entweder zu einem „Weltstaat“ oder zur Etablierung neuer politisch maßgebenden Einheiten führen könne. Einen Weltstaat lehnte er kategorisch ab, weil dieser nach seiner Definition nicht mehr politisch (strictu sensu auch kein „Staat“) sein könne: Wenn die Staatlichkeit innere Einheit (d.h. das Ende des „Politischen“ im Inneren) bedeutet, setzt das plurale "Politische“ mindestens zwei Staaten (oder andere, politisch maßgebende Einheiten) in der Welt voraus. Während er sich in der Weltpolitik für die Beibehaltung des Politischen einsetzte, ${ }^{4}$ richtete sich seine eigene Staatslehre gegen den inneren Pluralismus, den er qua souveräner Entscheidungen beseitigen wollte. ${ }^{5}$ Der Vielfalt der Staatenwelt korrespondiere laut ihm die antipluralistische Einheit des Staates.

Nach dem Westfälischen Frieden setzte sich der Staat als im Schmittschen Sinne maßgebende politische Einheit durch - d.h. als eine Einheit, welche durch physische Beseitigung der „Feinde“ („Vernichtung des Heterogenen“) eine interne Homogenität herbeiführe. ${ }^{6}$ Schmitt verstand den Staat als eine antipluralistische Einheit, welcher ,innerhalb des Staates und seines Territoriums eine vollständige Befriedigung herbeizuführen, "Ruhe, Sicherheit und Ordnung" herzustellen", d.h. zwischen „Freund“ und „Feind“ eine Entscheidung zu treffen fähig und willens sei. ${ }^{7}$ Er verband die Staatlichkeit mit der Notwendigkeit der internen Homogenität; Pluralismus herrsche demnach nicht in den Staaten, sondern nur zwischen ihnen. ${ }^{8}$ Deswegen nahm er den internen Pluralismus - als Folge der liberalen (Parteien-)Demokratie - als Verfallszeichen der Staatlichkeit wahr.9 Zuerst versuchte er diesen Verfall intern aufzuhalten, indem er einen qualitativ totalen Staat forderte - d.h. einen Staat, der den gesellschaftlichen Interessen und Gruppen überlegen sei und im politischen Sinne Entscheidungen treffe. ${ }^{10}$ Später wandte er sich aber der Frage zu, ob die Staatlichkeit überhaupt die geeignete Einheitskategorie für eine politische (plurale) Weltordnung sei.

4 Carl Schmitt, Begriff des Politischen, Duncker und Humblot, Berlin, 1991, p. 32., p. 54.

5 Ders., „Staatsethik und pluralistischer Staat”, Kant-Studien, 35, 1930/1-4, pp. $36 \mathrm{f}$.

6 Ders., Die geistesgeschichtliche Lage des heutigen Parlamentarismus, Duncker und Humblot, Berlin 1996, pp. 13f.

7 Ders., Begriff des Politischen, op. cit., p. 46.

8 Ders., „Staatsethik und pluralistischer Staat”, op. cit., pp. $29 \mathrm{ff}$.

9 Ebd., p. 28.

10 Ders., „Starker Staat und gesunde Wirtschaft”, in: ders., Staat, Großraum, Nomos. Arbeiten aus den Jahren 1916-1969, Duncker und Humblot, Berlin, 1995, pp. 74ff. 
Schmitt wird oft als ein etatistischer Denker bezeichnet - dabei wird es aber verkannt, dass er die Staatlichkeit als ein historisches Phänomen betrachtete. ${ }^{11}$ Er war also nicht der Meinung, dass nur Staaten politische Einheiten bilden und somit eine politische Weltordnung ermöglichen könnten. ${ }^{12}$ Insofern schrieb er dem in der europäischen Frühneuzeit erschienenen Phänomen des Staates keine Alleinherrschaft oder keine Absolutheit zu. ${ }^{13}$ Seine Beschreibung des Staates als die maßgebende Einheit des Politischen, welche fähig sei, im Inneren den Pluralismus zu beseitigen und nach außen hin „Freunde“ und „Feinde“ zu unterscheiden, ${ }^{14}$ bezog sich dementsprechend auf eine konkrete Epoche und einen konkreten Raum, d.h. auf das post-westfälische Europa. Angesichts der weltpolitischen Veränderungen - d.h. des Verfalls eines europäisch dominierten Völkerrechts - gelang er allerdings immer mehr zur Erkenntnis, dass selbst ein intern qualitativ totaler Staat sich in der Weltordnung nicht mehr durchzusetzen vermöge: Schmitt nahm ab Ende des 19. Jahrhunderts Veränderungen in der Weltpolitik wahr, welche neue politische Einheiten statt der bisherigen Staatlichkeit erforderlich gemacht hätten.

Seine Staatslehre ermöglichte ein post-staatliches Konzept. Weil er dem Staate das Politische vorausschickte, ${ }^{15}$ verstand er nicht den Staat, sondern das Politische als die ewige Grundkategorie menschlichen Zusammenlebens. Schmitt versuchte dementsprechend, die staatliche Einheit aus zwei Richtungen durch neue Konzepte zu ersetzen: Aus der Sicht der Außenpolitik bedürfe es mehrerer politischen Einheiten, damit eine universalistische Weltordnung vermieden werden könne; aus der Sicht der Innenpolitik bedürfe es einer starken politischen Einheit, welche dem Pluralismus einer demokratischen Gesellschaft ein Ende setzt. Das Ende der historischen Epoche der Staatlichkeit solle also nicht das Ende des Politischen bedeuten.

\section{2. Großraum als post-völkerrechtliche Einheit: Gegen ein Weltrecht}

Bevor die anti-staatliche Wende Schmitts näher untersucht wird (1. 4.), widme ich mich der Frage, warum Schmitt die Etablierung eines Weltrechts ablehnte, d.h. warum er meinte, ein anderes Völkerrecht entwickeln zu müssen. Wie oben bereits geschrieben, hielt Schmitt einen Weltstaat - d.h. eine politische Einheit der ganzen Welt - für eine contradictio in adjecto, die Begriffe "Welt" und „Staat" schließen sich bei ihm per definitionem aus, es sei denn, es treten neue außerplanetarischen politischen Einheiten neben der "Welt" als politische Einheit auf. Im Versuch, das Völkerrecht als „Weltrecht“ zu konzipieren, erblickte er die „Gefahr“ eines möglichen „Weltstaates“, der für ihn zwar einen begrifflichen

11 Ders., "Staat als ein konkreter, an eine geschichtliche Epoche gebundener Begriff”, in: ders., Verfassungsrechtliche Aufsätze aus den Jahren 1924-1954. Materialien zu einer Verfassungslehre, Duncker und Humblot, Berlin, 1985, pp. 375ff.

12 Adeel Hussain / Armin von Bogdandy, "Carl Schmitt's International Thought and the State”, MPIL Research Paper Series, 2018-34, p. 19.

13 Carl Schmitt, „Raum und Großraum im Völkerrecht”, in ders., Staat, Großraum, Nomos, op. cit., p. 240.

14 Ders., Begriff des Politischen, op. cit., pp. 54ff.

15 Ebd., p. 20. 
Widerspruch, aber eine hegemonial-politisch durchaus mögliche (von ihm befürchtete) Antwort auf die Erosion des „europäischen“ Völkerrechts darstellte.

Wenn man/frau auch bedenkt, dass etwa Hans Kelsen als einer der bekanntesten Theoretiker eines monistischen Völkerrechts die Staatlichkeit mit der Rechtsordnung vollkommen gleichsetzte („Identitätsthese“), ${ }^{16}$ liegt der Gedanke nahe, dass die Etablierung eines „Weltrechts“ eigentlich der Etablierung eines „Weltstaates“ - gerade im Kelsenschen Sinne - gleichkäme. Als politisch engagierter Mensch hätte Kelsen einen „Weltstaat“ in der Tat unterstützt. ${ }^{17}$ Als realistischer Wissenschaftler verwarf er aber - aufgrund der religiösen, sprachlichen, historischen, ökonomischen (usw.) Unterschiede - die Wahrscheinlichkeit eines „Weltstaates“. ${ }^{18}$ Er setzte hingegen auf das Völkerrecht (und seine Organisationen) als gestaltende Kraft, welche die Staaten zu einer Friedensgemeinschaft formen könnte. ${ }^{19}$ Dass Kelsen dabei „Weltstaat“ und Völkerrecht voneinander getrennt und das Völkerrecht nicht explizit als "Weltstaat" bezeichnete, verletzt allerdings seine "Identitätsthese“, nach welcher der Staat nichts anderes als ein Synonym (eine Personifizierung) für die Rechtsordnung sei; oder dass Kelsen aufgrund von Fakten (d.h. aufgrund der fehlenden Wahrscheinlichkeit und Wirksamkeit) die normative Kategorie eines „Weltstaates“ ausschloss, lief seiner Sein-Sollen-Trennung entgegen - diese Schwächen der Kelsenschen Völkerrechtslehre seien hier aber dahingestellt.

Kelsen hatte ein einheitliches Rechtsbild: Das Recht gestalte und konkretisiere sich stufenweise, die Rechtsordnung stelle demnach einen Stufenbau dar, ${ }^{20}$ in dem das einzelstaatliche Recht dem Völkerrecht untergeordnet sei.21 Dass sich die Staatenwelt immer mehr zu einer völkerrechtlichen Rechtsordnung entwickeln soll, ergibt sich aus dem monistischen Völkerrechtsverständnis, welches das Völkerrecht und das staatliche Recht als eine Rechtsordnung versteht. Besonders in der Wiener Rechtstheoretischen Schule war dieser Gedanke vorhanden, welcher sowohl den rechtstheoretischen Grundlagen als auch den politischen Zielen der Schule entsprach. ${ }^{22}$ Dem Monismus lag allerdings ein „Erkenntnisreduktionismus“ zugrunde, der alles Recht nach dem Modell des staatlichen Rechts konzipierte, als ob das Recht nur als logisch widerspruchsfreie, strukturell geschlossene Einheit gedacht werden könnte. ${ }^{23}$ Diese rechtserkenntnistheoretische Position schließt eine pluralistische Perspektive - etwa die Möglichkeit von mehreren,

16 Hans Kelsen, Der soziologische und der juristische Staatsbegriff. Kritische Untersuchung des Verhältnisses von Staat und Recht, Mohr Siebeck, Tübingen, 1922, pp. 205ff., p. 252.; ders., Allgemeine Staatslehre. Studienausgabe der Originalausgabe 1925. Hg. von Matthias Jestaedt, Mohr Siebeck / Verlag Österreich, Tübingen / Wien, 2019, p. 14., p. 59.

17 Ders., Peace through Law, North Carolina UP, Chapel Hil, 1944, p. 4 f.

18 Ebd., p. 8ff.

19 Ebd., p. 12.

20 Ders., Reine Rechtslehre. Studienausgabe der 1. Auflage 1934. Hg. von Matthias Jestaedt), Mohr Siebeck, Tübingen, 2008, pp. 84ff.

21 Ebd., pp. $158 \mathrm{ff}$.

22 François Rigaux, „Hans Kelsen on International Law”, European Journal of International Law, 9, 1998, p. 340.

23 Ebd., p. 334. 
neben- sogar gegeneinander geltenden Rechtsordnungen - aus. ${ }^{24}$ In diesem Sinne ist Schmitts partikulares Rechtsverständnis aussagekräftiger in puncto Rechtsvielfalt. 25

Kelsen rechtfertigte den Monismus - d.h. die These, dass das Recht nur als Einheit erkannt werden kann/soll - als epistemologische Notwendigkeit: „Die Einheit des Erkenntnisstandpunktes fordert gebieterisch eine monistische Anschauung". ${ }^{26}$ Eine wissenschaftliche Beschäftigung mit dem Recht - sowohl als Völker- als auch als Staatsrecht - erfordere demnach einen einheitlichen Gegenstand. Die Frage, ob dem Völker- oder dem Staatsrecht das Primat in der monistischen Rechtseinheit gebühre, lässt sich jedoch nicht eindeutig aufgrund der Logik der „Reinen Rechtslehre“ entscheiden. Kelsen verwies darauf, dass beide Optionen (das Primat des Völker- wie jenes des Staatsrechts) wissenschaftlich trag- und vertretbar seien, weswegen das Primat des Völkerrechts nur politisch postuliert werden könne. ${ }^{27}$ Das Primat des Staatsrechts würde aber nach der Logik der „Reinen Rechtslehre“ zu absurden Ergebnissen führen, das Völkerrecht wäre den einzelnen Staatsrechtsordnungen unterstellt, was praktisch der Hegelschen Idee entspräche, das Völkerrecht sei bloß „das äußere Staatsrecht“, d.h. es ergebe sich aus der absoluten Macht des Staates. $^{28} \mathrm{Um}$ diese staatsabsolutistische Perspektive zu vermeiden, bejahte Kelsen - schon in der Zwischenkriegszeit - das Primat des Völkerrechts, ${ }^{29}$ indem er die staatliche Souveränität - als mit dem Völkerrechtsprimat unvereinbare Eigenschaft - dekonstruierte. ${ }^{30}$ In diesem Sinne bezeichnete er das staatliche Recht als "eine völkerrechtsunmittelbare, relativ zentralisierte Teilrechtsordnung“. ${ }^{31}$ Die Staatlichkeit als Teilrechtsordnung setzt nicht nur den Monismus, sondern auch das Primat des Völkerrechts voraus - insofern ist das

24 Alexander Somek, „Stateless Law: Kelsen's Conception and its Limits”, Oxford Journal of Legal Studies, 26, 2006/4, pp. 754ff.

25 Jörg Kammerhofer beweist aber, dass die antipluralistische Einheitsperspektive, welcher ein absolutes Verständnis von einem, richtigen Recht zugrunde liege, auch nach der Logik der „Reinen Rechtslehre” nicht notwendig sei: Kelsens Normlehre schließe nämlich Widersprüche zwischen den Normen nicht aus, insofern seien mehrere Normsysteme gleichzeitig möglich; Jörg Kammerhofer: „Kelsen - Which Kelsen? A Reapplication of the Pure Theory to International Law”, Leiden Journal of International Law, 22, 2009/2, pp. $243 f$.

26 Hans Kelsen, „Das Problem der Souveränität und die Theorie des Völkerrechtes. Ein Beitrag zu einer reinen Rechtslehre”, in Matthias Jestaedt gem. mit dem Hans-Kelsen-Institut Wien (Hg.), Hans Kelsen Werke. Bd 4: Veröffentlichte Schriften 1918-1920, Mohr Siebeck, Tübingen, 2013, p. 385. [Hervorhebung im Orig.]

27 Dazu, dass Kelsens Position bezüglich des Primats des Völkerrechts, eine politische Entscheidung sei, siehe u.a. András Jakab, „Kelsens Völkerrechtslehre zwischen Erkenntnistheorie und Politik", in Hauke Brunkhorst / Rüdiger Voigt (Hg.), Rechts-Staat. Staat, internationale Gemeinschaft und Völkerrecht bei Hans Kelsen, Nomos, Baden-Baden, 2008, pp. $195 f$.

28 Georg Wilhelm Friedrich Hegel, Grundlinien der Philosophie des Rechts oder Naturrecht und Staatswissenschaft im Grundrisse, Suhrkamp, Frankfurt/M, 1970, pp. 497ff. (§ 330ff.)

29 Kelsen, „Das Problem der Souveränität und die Theorie des Völkerrechtes”, op. cit., p. 567.

30 Ebd., p. 367.

${ }^{31}$ Ders., Reine Rechtslehre, op. cit., p. 158. 
Völkerrechtsprimat nicht weniger wissenschaftlich begründet in der „Reinen Rechtslehre" als der Monismus selbst. 32

Dass die Debatte um Monismus und Völkerrechtsprimat auch praktische Konsequenzen für die Weltordnung hat, zeigte sich etwa in der Frage, wann ein Krieg erlaubt sei: Liegt die Entscheidung darüber, ob ein Krieg rechtens geführt wird, bei den Staaten, oder bei einem Völkerrecht, das kriegerische Handlungen von Staaten - entgegen dem Staatswillen - verurteilen, sogar sanktionieren darf? Das spezielle Völkerrecht der Zwischenkriegszeit verfolgte das Konzept des „bellum iustum“,33 nach dem der Krieg eine illegale (völkerrechtswidrige) Handlung des Staates darstellen kann. Kelsen war allerdings skeptisch hinsichtlich der Frage, ob das Völkerrecht - zumindest auf seiner damaligen Entwicklungsstufe - über die Rechtsmäßigkeit (und dadurch das Erlaubnis) eines Krieges entscheiden kann. Er meinte, dass diese Frage noch politischer und nicht juristischer Natur sei. ${ }^{34}$ Kelsens Skepsis bezog sich also auf die Effektivität des Völkerrechts. Im Gegensatz dazu hob Schmitt die "Gefahr“ eines Völkerrechts hervor, das sich anmaßen würde, über Krieg und Frieden jenseits der Staatswillen zu disponieren. Er meinte nämlich - im Einklang mit seinem antiuniversalistischen und antiabstrakten Rechtverständnis (1.3.) -, dass die Frage, was Krieg und Frieden sei, in einer universalistischen, vom Primat des Völkerrechts bestimmten Welt von einer hegemonialen Macht beantwortet würde. Damit wollte er das universalistische „Weltrecht“ und dessen Friedenskonzept ganz im Sinne von heutigen linken und neurechten Theorien (dazu noch näheres im Ausblick) - als Verschleierung partikularer Interessen gewisser Mächte entlarven:

\begin{abstract}
„[W]er stellt den Frieden auf der Erde her? Wir alle wünschen den Frieden; aber die Frage ist leider die: wer entscheidet darüber, was Frieden ist, wer darüber, was Ordnung und Sicherheit ist, wer darüber, was ein erträglicher und was ein unerträglicher Zustand [ist]?“ 35
\end{abstract}

Ob Schmitt wirklich den Frieden wollte, lässt sich allerdings bezweifeln. Eine Welt ohne Krieg wäre für ihn eher ein Horrorszenario gewesen, ${ }^{36}$ sie hätte nämlich des politischen Konfliktes (des Krieges) entbehrt bzw. sie hätte die Staaten als maßgebende politische Einheiten zu einfachen Teilrechtsordnungen (à la Kelsen) degradiert. Im Gegensatz dazu wollte Schmitt ein Völkerrecht

32 Besonders der Kelsen-Schüler Alfred Verdroß vertrat das Primat des Völkerrechts, indem er die Existenz völkerrechtlicher Rechtsnormen bewies, deren Ursprung außerhalb (oberhalb) des staatlichen Rechts liegen; vgl. Alfred Verdroß, Die Einheit des rechtlichen Weltbildes auf Grundlage der Völkerrechtsverfassung, Mohr Siebeck, Tübingen, 1923, pp. 119f., pp. 126ff.

33 Friedensvertrag von Versailles (1919), Art. 231; Völkerbund-Beschluss (1924), Art. 15; Kellog-Briand-Pakt (1928).

34 Kelsen, Law and Peace in International Relations, Harvard UP, Cambridge MA, 1948, pp. 47f.

35 Carl Schmitt, „Völkerrechtliche Formen des modernen Imperialismus (1932)”, in: ders., Positionen und Begriffe im Kampf mit Weimar - Genf - Versailles 1923-1939, Hanseatische, Hamburg, 1940, p. 176.

36 Gerardo Tripolone, „La doctrina de Carl Schmitt sobre el derecho internacional”, Anuario Mexicano de Derecho Internacional, 14, 2014, pp. 353f. 
herausarbeiten, welches den Staaten (oder den anderen politisch maßgebenden Einheiten) das Kriegsrecht nicht abspricht. Schmitt dachte sowohl die Weltordnung als auch den Staat vom Krieg her: Die Aufgabe des Staates bestehe zwar in der Beendigung des (Bürger-)Krieges. Aber der Krieg dürfe aus der Weltpolitik nicht verschwinden, weil Schmitt - der keinen einzigen Tag in seinem Leben auf Kriegsfront verbrachte ${ }^{37}$ - den Krieg für unabdingbar / unvermeidbar hielt. Der Krieg ist zwar Ausnahme, aber Schmitt denkt die Ausnahme aus dem Recht nicht weg, er stellt sie vielmehr in den Vordergrund seiner ganzen Rechtslehre: „Die Ausnahme ist interessanter als der Normalfall. [...] [S]ie bestätigt nicht nur die Regel, die Regel lebt überhaupt nur von der Ausnahme“.38 Die Ausnahme als souveräne Entscheidung diene innerhalb des Staates der Beseitigung des Pluralismus, während sie als Krieg in der Weltpolitik den Pluralismus bewähre. Die Ausnahme garantiere demnach eine antipluralistische Innen- und eine pluralistische Weltordnung bei Schmitt.

In diesem Sinne meinte er, dass ein weltfriedensliebendes „Weltrecht“ den Krieg zwar nicht abschaffen könne - dieser gehöre so grundliegend zur menschlichen Natur und Geschichte -, aber ihn durch eine juristische Verurteilung / Unmöglichmachung - wie in der Friedensordnung des Völkerbundes angestrebt wurde - enthemmen würde. ${ }^{39}$ Ein moralisch aufgeladenes Kriegskonzept erschwere, so Schmitt, auch die Rückbindung der Kriegsparteien in die politische Weltordnung. 40 Er meinte daher, dass das Völkerrecht (und ein völkerrechtlicher Frieden) den Krieg - und die kriegsführenden Parteien - nicht verurteilen, bestrafen, sondern eine temporäre Friedensordnung herstellen solle, in welcher Sieger und Verlierer sich wiederfinden bzw. künftig auch weitere Kriege miteinander führen können. ${ }^{41}$ Diese Gedanken folgen nicht nur aus Schmitts bellizistischem Politik-, sondern auch seinem anti-universalistischen (partikularistischen) Rechtsverständnis: Wenn das Recht, wie Schmitt behauptet, immer konkret, situativ sei und für jede Zeit, für jedes Volk etwas anderes bedeute, liegt die Schlussfolgerung nahe, dass ein universalistisches Friedensprinzip gewisse partikularen Interessen tarne.

\section{3. Großraum als partikulare Einheit: Für ein raumbezogenes Völkerrecht}

Um Schmitts Kritik an einem neuen „Weltrecht“ verstehen zu können, müssen wir sein Rechtsverständnis mit betrachten. Im Gegensatz zu Hans Kelsen konzipierte Schmitt das Recht nicht als ein abstraktes Normsystem. Kelsen

37 Den Ersten Weltkrieg verbrachte Schmitt in München, wo er zuerst die militärische Grundausbildung in einer Kaserne leistete und dann als Zensor arbeitete; daneben verkehrte er in den bohemischen Kreisen von Schwabing; zu dieser Zeit siehe Carl Schmitt, Die Militärzeit 1915 bis 1919. Tagebuch Februar bis Dezember 1915, Aufsätze und Materialien. Hg. von Ernst Hüsmert und Gerd Giesler, Akademie, Berlin, 2005.

38 Ders., Politische Theologie. Vier Kapitel zur Lehre von der Souveränität, Duncker und Humblot, Berlin, 2015, p. 21.

39 Ders., Der Nomos der Erde im Völkerrecht des Jus Publicum Europaeum, Duncker und Humblot, Berlin, 1997, pp. $114 \mathrm{f}$.

40 Ebd., p. 158.

41 Ders., „Die Raumrevolution. Durch den totalen Krieg zu einem totalen Frieden”, in ders., Staat, Großraum, Nomos, op. cit., p. 389. 
verstand das Recht als ein System, das einerseits zeit- und raumungebunden, andererseits nicht aufgrund dessen Inhalts gelte. ${ }^{42}$ Schmitt hingegen lehnte eine solche logisch-rationalistische Herangehensweise ab, weil „[j]ede rationalistische Deutung [des Rechts] die Unmittelbarkeit des Lebens fälschen [würde]“. ${ }^{43}$ In direktem Angriff auf die "Reine Rechtslehre" behauptete er, dass diese vor der wichtigen Frage, wer das Recht bestimmen kann, „den Kopf in den Sand eines reinen Normativismus" stecke. ${ }^{44}$ Schmitt begriff nämlich das Recht nicht als eine allgemein beschreibbare, universal (überall) gleiche Funktionsweise, sondern als eine konkrete Ordnung, die nur in einer bestimmten Zeit, an einem bestimmten Ort, für ein bestimmtes Volk gültig sein könne. Das Recht war für ihn immer situativ, sein Sinn ergebe sich daher nicht allgemein, sondern in konkreten Situationen. ${ }^{45}$ Gerade in der Vielfalt der Völker und ihren juristischen Vorstellungen sah er einen Beweis für sein partikulares, anti-universelles Rechtsverständnis:

\begin{abstract}
„Die Wahrheit, daß alles Recht in erster Linie konkrete Ordnung ist, während Normen und Regelungen ihren Sinn und ihre Logik nur im Rahmen einer konkreten Ordnung erhalten, bewährt sich im Zusammenleben der Völker am stärksten und unmittelbarsten“. 46
\end{abstract}

Schmitt meinte also, dass das Recht - wie alle gesellschaftlichen Phänomene - partikulare Interessen ausdrücke. Insofern wollte er den Dualismus zwischen „Partikularismus“ und „Universalismus“ als Kampf um die Deutungshoheit über die Begriffe entlarven, als ob dem „Universalismus“ ebenso nur partikulare Interessen zugrunde lägen - bloß verschleiert. Daher verkündete er: „Ein Volk ist erst dann besiegt, wenn es sich dem fremden Vokabularium, der fremden Vorstellung von dem, was Recht, insbesondere Völkerrecht ist, unterwirft." 47 Schmitt war deswegen überzeugt, dass der normative und abstrakte Universalismus der „Reinen Rechtslehre“ im Bereich des Völkerrechts die partikularen Interessen gewisser Mächte (nämlich der Siegermächte nach dem Ersten Weltkrieg) verschleiere. ${ }^{48}$ Mit seiner Hegemoniekritik nahm Schmitt die postmoderne Rechtskritik vorweg, welche ebenso von der notwendigen Machtund Positionsbedingtheit des Rechts ausgeht: Es gebe demnach kein abstraktes Recht, nur „universalistisch“ verschleierte Partikularinteressen. Wie Schmitt schreibt: Wer Macht hat, diktiere auch die Begriffe - d.h. "Caesar dominus et

42 Kelsen, Reine Rechtslehre, op. cit., pp. 74 f.

43 Carl Schmitt, „Die politische Theorie des Mythus (1923)”, in: ders., Positionen und Begriffe im Kampf mit Weimar-Genf-Versailles, op. cit., p. 13.

44 Ders., „Über die innere Logik der Allgemeinpakte auf gegenseitigen Bestand (1935)”, in: ders., Positionen und Begriffe im Kampf mit Weimar-Genf-Versailles, op. cit., p. 206.

45 Ders., Politische Theologie, op. cit., p. 19.

46 Ders., „Die Auflösung der europäischen Ordnung im "International Law" (1890-1939)”, in ders., Staat, Großraum, Nomos, op. cit., p. 382.

47 Ders., „Völkerrechtliche Formen des modernen Imperialismus”, op. cit., p. 179.

48 Anthony Carty, „Carl Schmitt's Critique of Liberal International Legal Order Between 1933 and 1945”, Leiden Journal of International Law, 14, 2001/1, p. 32. 
supra grammaticam". ${ }^{49}$ Er wollte diese Machtbezogenheit der Begriffe an der Frage veranschaulichen, wann ein Krieg vorliegt - ihm zufolge werde diese Frage in einer universalistischen Weltordnung nach den partikularen Interessen der einzig übrig gebliebenen hegemonialen Macht beantwortet:

\begin{abstract}
„Der Imperialismus führt keine nationalen Kriege, diese werden vielmehr geächtet; er führt höchstens Kriege, die einer internationalen Politik dienen; er führt keine ungerechten, nur gerechte Kriege; ja, wir werden noch sehen, daß er überhaupt nicht Krieg führt, selbst wenn er mit bewaffneten Truppenmassen, Tanks und Panzerkreuzern das tut, was bei einem andern selbstverständlich Krieg wäre."50
\end{abstract}

Als Alternative zum „imperialistischen“ Universalismus forderte Schmitt allen Völkern das „Recht“ ein, ihr Leben und ihre Politik nach ihren eigenen Begriffen bestimmen zu können - „ein Ausdruck echter politischer Macht“ bestehe nämlich ihm zufolge darin, „wenn ein großes Volk die Redeweise und sogar die Denkweise anderer Völker, das Vokabularium, die Terminologie, die Begriffe von sich aus bestimmt“. ${ }^{51}$ In diesem Satz klingt übrigens nicht bloß der Wunsch nach einer (vermeintlichen) Selbstbestimmung, sondern auch das Ziel einer erwünschten deutschen Hegemonie über andere Völker mit - so wie es die USA nach dem Ersten Weltkrieg in Europa gemacht hätte. ${ }^{52}$

Sein anti-abstraktes, konkretes Rechtsverständnis entnahm Schmitt einerseits dem Nomos-Konzept des Altphilologen Hans Bogner, der mit dem „Nomos“ die konkrete Lebensordnung der hellenischen Welt beschreiben wollte; 53 andererseits der Volksnomologie des protestantischen Theologen Wilhelm Stapel, der dem abstrakten Recht den „Nomos” als raumgebundenes Ordnungskonzept entgegenstellte. ${ }^{54}$ Nach dem Schmittschen Nomoskonzept stelle die Landnahme den Ur-Akt des Rechts dar, welche die Grenzen des dort gültigen Rechts festmache: „Eine Landnahme begründet Recht nach doppelter Richtung, nach Innen und nach Außen”. ${ }^{5}$ Der "Nomos“ bedeute die boden- und volksgebundene Ordnung eines konkreten Ortes:

„Nomos [...] kommt von nemein, einem Wort, das sowohl "Teilen" wie auch "Weiden" bedeutet. Der "Nomos" ist demnach die unmittelbare Gestalt, in

49 Schmitt, „Völkerrechtliche Formen des modernen Imperialismus”, op. cit., p. 179. [Hervorhebung von mir - P.T.]

50 Ebd., p. 177.

51 Ebd., p. 179.

52 Ders., „Großraum gegen Universalismus (1939)”, in: ders., Positionen und Begriffe im Kampf mit Weimar-Genf-Versailles, op. cit., p. 302.

53 Raphael Gross, Carl Schmitt und die Juden. Eine deutsche Rechtslehre, Suhrkamp, Frankfurt/M, 2005, pp. 98ff.

54 Felix Blindow, Carl Schmitts Reichsordnung. Strategie für einen europäischen Großraum, Akademie, Berlin, 1999, pp. 141f.; Martti Koskenniemi, The Gentle Civilizer of Nations. The Rise and Fall of International Law 1870-1960, Cambridge UP, Cambridge, 2002, p. 415.

55 Carl Schmitt, Der Nomos der Erde im Völkerrecht, op. cit., p. 16. 
der die politische und soziale Ordnung eines Volkes raumhaft sichtbar wird". 56

Was in der Nomoslehre als Ur-Akt des Rechts beschrieben wird, entspricht dem politischen Ur-Akt von Unterscheidung zwischen „Freund“ und „Feind“, den Schmitt als Grundvoraussetzung jeglicher politischen Einheit erachtete: Einer Rechtsordnung gehe die Entscheidung darüber voraus, wer dazu gehört und wer nicht. ${ }^{5}$ Die Landnahme ist dementsprechend die Festlegung des Raumes, in dem die „Feinde“ vernichtet werden, damit sich ein konkretes, volkhaftes Recht („Nomos“) etablieren könne. Das räumlich-konkrete Konzept schließt zugleich ein universelles „Weltrecht“ als Völkerrecht aus - der „Nomos“ ermöglicht vielmehr eine politische (d.h. plurale) Weltordnung geschlossener Räume mit ihren jeweiligen, ihnen eigenen „Nomoi“. Der „Nomos“ markiert somit die Grenze zwischen den Völkern und zwischen den Räumen. ${ }^{58}$ Dabei ist es freilich nicht zu vergessen, dass Wilhelm Stapel seine Nomoslehre als ein antisemitisches Konzept entwickelte: Indem er jeden Völkern unterschiedliche Nomoskonzepte zuschrieb, wollte er vor allem den vermeintlichen Wesensunterschied der christlichen Völker zum „staatenlosen“ Judentum beweisen. ${ }^{59}$ In diesem Sinne betonte auch Schmitt, dass das Recht keine allgemeine Funktion, sondern eine raum- und volksgebundene Denkweise sei, welche sich bei allen Völkern variiere. Das abstrakte Rechtsdenken, welches zu einem universellen „Weltrecht" führen würde, sei hingegen, so Schmitt, typisch nur für die Völker, „die ohne Boden, ohne Staat, ohne Kirche, nur im "Gesetz" existieren". 60

Im nationalsozialistischen (Völker-)Recht, dem er sich verpflichtete, ${ }^{61}$ sah er die partikularistische Abrechnung mit der formalistisch-positivistischen Rechtslehre: „Alles, was situationsmäßig sinnvoll sein konnte, z.B. die Clausula rebus sic stantibus oder gar der Vorbehalt der vitalen Interessen, war ihnen [d.h. den Vertretern der Reinen Rechtslehre - P.T.] verdächtig."62 Er machte demgegenüber räumliche Begrenztheit und Konkretheit des Rechts als Wesen eines (von ihm vollkommen mitgetragenen) nationalsozialistischen Rechtsverständnisses fest: „Das nationalsozialistische Recht ist kein welt- und menschheitsumfassendes Recht und will es nicht sein. [...] Es ist nicht universal, nicht international...". ${ }^{63}$ Dieses Rechtskonzept richtete sich gegen die abstrakten Ideen:

56 Ebd., p. 39. [Hervorhebung im Orig.]

57 Ders., Verfassungslehre, Duncker und Humblot, Berlin, 2017, p. 23., p. 76.

58 William Hooker, Carl Schmitt's International Thought. Order and Orientation, Cambridge UP, Cambridge, 2009, p. 72.

59 Wilhelm Stapel, Sechs Kapitel über Christentum und Nationalsozialismus, Hanseatische, Hamburg / Berlin, 1931, p. 14.

60 Carl Schmitt, Über die drei Arten des rechtswissenschaftlichen Denkens, Duncker und Humblot, Berlin, 1993, p. 9.

${ }^{61}$ Ders., „Nationalsozialistisches Rechtsdenken”, Deutsches Recht, 4, 1934, p. 225.

62 Ders., Nationalsozialismus und Völkerrecht, Junker und Dünnhaupt, Berlin, 1934, p. 11.

63 Ders., „Die nationalsozialistische Gesetzgebung und der Vorbehalt des "ordre public" im Internationalen Privatrecht”, Zeitschrift der Akademie für Deutsches Recht, 6, 1936, p. 206. 
„Für uns gibt es weder raumlose politische Ideen noch umgekehrt ideenlose Räume oder Raumprinzipien. $\mathrm{Zu}$ einer bestimmbaren politischen Idee wiederum gehört, daß ein bestimmtes Volk sie trägt und daß sie einen bestimmten Gegner im Auge hat, wodurch sie die Qualität des Politischen erhält". 64

Schmitt lehnte deswegen ab, das europäisch entstandene Völkerrecht in ein universalistisches „Weltrecht“ weiterzudenken.65 Dieses wäre nämlich „ein unterschiedsloses, raumaufhebendes Weltrecht“".66 Er bemängelte die Raum- und Volksungebundenheit des „Weltrechts“, das daher einerseits „echte Raumausgrenzungen aufhebt und die Unterscheidungslinien durch die Völker hindurchgehen lässt", 67 andererseits - wie er meinte - eigentlich nur den angelsächsischen, hegemonialen Interessen diene.68 Ein neues „International Law" - wie er das neue Völkerrecht auch in seinen deutschsprachigen Aufsätzen spöttisch bezeichnete ${ }^{69}$ - war für ihn „ein systemloses Nebeneinander von Normen; im übrigen ein ungeordnetes, räumlich und völkisch zusammenhangloses Nebeneinander [...] von Staaten“, d.h. „ein Sprung in das Nichts einer bodenlosen Allgemeinheit".70 Schmitt war besorgt, dass ein raumungebundenes "Weltrecht" das raumgebundene Völkerrecht - nämlich das Völkerrecht der europäischen Staatenwelt - ersetzen würde. ${ }^{71}$ Mit seiner Großraumlehre wollte er dieser universalistischen Tendenz entgegenwirken, indem er die Raumgebundenheit im Völkerrecht noch mehr in den Vordergrund rückte.

Konsequenterweise schlug er die räumliche Aufteilung der Völkerrechtsordnung vor: Jeder Großraum solle demnach sein eigenes „Völkerrecht” besitzen. Er maß somit dem Begriff „Völkerrecht” eine neue, raumhafte und völkische Bedeutung bei, weil es sich dabei nicht mehr um ein supranationales Recht zwischen (unter) allen Völkern handelte, sondern um das Recht konkreter Völker, die in einem Großraum zusammenleben. Dieses innergroßräumliche „Völkerrecht” ist eigentlich ein „Volkrecht”, es bringt nämlich den herrschenden Willen des hegemonialen Volkes zum Ausdruck, ${ }^{72}$ um dessen „Reich” herum sich der Großraum etablieren solle.

64 Ders., Völkerrechtliche Großraumordnung mit Interventionsverbot für raumfremde Mächte. Ein Beitrag zum Reichsbegriff im Völkerrecht, Duncker und Humblot, Berlin, 1991, p. 29.

65 Schmitt hatte allerdings ein idealisiertes - von historischen Fakten nicht belegbares - Bild vom Jus Publicum Europaeum als einem europäischen, inner-staatlichen Völkerrecht, welches den Krieg gehemmt, entmoralisiert hätte; vgl. Benno Gerhard Teschke, „Fatal attraction: a critique of Carl Schmitt's international political nd legal theory”, International Theory, 3, 2011/2, pp. 203ff.

66 Schmitt, „Raum und Großraum im Völkerrecht”, op. cit., p. 250.

67 Ebd., p. 249.

68 Ebd., p. 250.

69 Ders., „Die Auflösung der europäischen Ordnung im "International Law" (1890-1939), op. cit., p. 378.

70 Ebd., p. 377. [Hervorhebung von mir - P.T.]

71 Ebd., p. 372.

72 Michael Stolleis, Geschichte des öffentlichen Rechts in Deutschland. Bd. 3: Staats- und Verwaltungsrechtswissenschaft in Republik und Diktatur 1914-1945, Beck, München, 1999, p. 383. 
Im Gegensatz zu Kelsen, der das Völkerrecht ernst nahm ${ }^{73}$ - d.h. er konzipierte es in der Tat als Recht aller Völker, welches dem staatlichen Recht vorangestellt ist -, ist es nicht klar, wie das Schmittsche Konzept überhaupt eine Weltordnung - jenseits der Etablierung der voneinander antagonistisch getrennten Großräume - herbeigeführt hätte. ${ }^{74}$ Die nationalsozialistische Völkerrechtslehre erkannte diese Problematik ebenso, sie radikalisierte aber die Schmittsche Großraumordnung dahin, dass ein gemeinsames Völkerrecht aufgrund der „rassischen“ Differenzen unter den Völkern - überhaupt nicht möglich oder wünschenswert sei: Weil das Völkerrecht selbst rassisch bestimmt sei, so der SS-Völkerrechtler Norbert Gürke, „könnte bezweifelt werden, daß es auch zwischen Völkern verschiedener rassischer Zusammensetzung zu völkerrechtlichen Verkehrsformen kommen kann“. ${ }^{75}$

\section{4. Großraum als post-staatliche Einheit: Gegen staatliche Souveränität}

Schmitt stellte zwei Tendenzen im Völker- und Staatsrecht fest: Einerseits verwandele sich das klassische, europäisch gedachte Völkerrecht zu einem universalistischen „Weltrecht“; andererseits setze sich die Souveränität jeglicher Staaten als Grundprinzip des Völkerrechts durch.76 Eine zersplitterte, geschlossen organisierte Staatenwelt korrespondiere demnach der Entstehung eines universalistischen Völkerrechts: „Je schärfer sich der Staat als territorial geschlossene, klein- oder mittelräumige zentralistische Organisation entwickelt, um so mehr verwandelt sich das Völkerrecht in ein zwischen-staatliches Recht". ${ }^{77}$

Schmitt konstatierte einen unüberbrückbaren Wesensunterschied zwischen dem räumlichen Recht der konkreten Staaten und dem raumungebundenen Recht einer abstrakten „Welt“. ${ }^{78}$ Dieser Dualismus bilde „das Hauptproblem der Völkerrechtswissenschaft“. ${ }^{79}$ Schmitt verstand in diesem Sinne die Großraumlehre als seinen Beitrag zur (Auf-)Lösung der Problematik. Er hob den Dualismus zwischen Staatsrecht und „Weltrecht“ dialektisch auf: Er relativierte das Recht der einzelnen Staaten, um ein neues, konkretes Völkerrecht begründen zu können. Daher forderte er „die Entthronung des Staatsbegriffes auf dem Wege eines Vorstoßes gegen den Souveränitätsbegriff“. $80 \mathrm{Er}$ meinte also, dass sich die Etablierung eines „Weltrechts“ nur durch die Überwindung der „alten“ Staatenwelt und ihres Prinzips von Staatssouveränität aufhalten lasse. Als Alternative zu einem „Weltstaat“ als neuem „Weltrecht“ entwickelte er sein Konzept der Großraumlehre. Die Großräume seien demnach die neuen politisch

73 Charles Leben, „Hans Kelsen and the Advancement of International Law”, European Journal of International Law, 9, 1998, p. 289.

74 Hussain / von Bogdandy, „Carl Schmitt's International Thought and the State”, op. cit., p. 27.

75 Norbert Gürke, Volk und Volkrecht, Mohr Siebeck, Tübingen, 1935, p. 99.

76 Schmitt, „Raum und Großraum im Völkerrecht”, op. cit., p. 251.

77 Ders., „Die Auflösung der europäischen Ordnung im "International Law" (1890-1939)", op. cit., p. 378.

78 Ders., „Raum und Großraum im Völkerrecht”, op. cit., p. 241.

79 Ders., „Die Auflösung der europäischen Ordnung im "International Law" (1890-1939)”, op. cit., p. 379.

80 Ders., Völkerrechtliche Großraumordnung, op. cit., p. 55. 
maßgebenden Einheiten, 81 welche den Pluralismus in der Welt (somit das "Politische“ in der Weltordnung), zugleich aber die Einheit innerhalb des Großraumes gewähren würden. ${ }^{82}$ Seine Großraumlehre stellt insofern auch einen wissenschaftlichen Angriff auf die Staatlichkeit als politisches Organisationsprinzip dar.

Auch wenn Schmitt und Kelsen gleichzeitig von der Notwendigkeit der Relativierung der Staatssouveränität schrieben, war die Richtung (und der Zweck) der Relativierung bei den zwei Autoren vollkommen unterschiedlich. Kelsen erkannte das Problem, dass die Ausschließlichkeit der staatlichen Souveränität eine strukturelle Schwierigkeit für ein universelles, monistisch gedachtes, den staatlichen Rechtsordnungen vorausgehendes Völkerrecht bereite. ${ }^{83}$ Daher stellte er die Souveränität infrage. Einerseits meinte er, dass die Souveränität eigentlich die Eigenschaft der als Staat personifizierten Rechtsordnung sei. ${ }^{84}$ Andererseits wies er darauf hin, dass sich die Souveränität der „staatlichen“ Rechtsordnungen in einer Völkerrechtsordnung nicht mehr als Grundkonzept aufrechterhalten lasse, weil der absolute Begriff der Souveränität andere Souveränitäten ausschließe, insofern der Anerkennung anderer Staaten bzw. ihrer gemeinsamen Eingliederung in eine Völkerrechtsordnung im Wege stehe. ${ }^{85}$ Kelsen lehnte also die Souveränität $a b, 86$ weil er die absolute politische Macht der Staaten als Hindernis für die Etablierung einer Völkerrechtsordnung erachtete.

Im Gegensatz zu Kelsen betrachtete Schmitt die staatliche Souveränität nicht mehr als Hindernis für die Etablierung einer Völkerrechtsordnung - was eher eine rechtshistorische als eine rechtstheoretische Position war -, deswegen bemühte er sich, eine neue Machtform zu begründen, die auch in der Weltpolitik die absolute Macht eines konkreten Volkes über einen konkreten Raum bewahren könne. Er verneinte die Souveränität, weil die souveränen Staaten ihre absolute Macht in der Weltpolitik nicht mehr zur Geltung zu bringen imstande gewesen seien. Schmitt dachte daher die staatliche Souveränität in ein neues Konzept weiter, in dem die angeblich verlorengegangene absolute Macht der (früh)neuzeitlichen Staatlichkeit in einer anderen politischen Einheitsform zurückgewonnen werden könne. Die Schmittsche Großraumlehre erweist sich demnach nicht nur als ein anti-weltrechtliches und anti-staatliches, sondern auch als ein souveränitätsbewahrendes Konzept - die Souveränität des Großraumes gebühre aber nicht allen Völkern, sondern nur den großen, die fähig sind, ein Reich (und um das Reich herum einen Großraum) zu gründen. Der Versuch, die Etablierung eines „Weltrechts“ zu verhindern, ergänzt sich bei ihm denknotwendig mit der Kritik an der Staatsbezogenheit des bestehenden Völkerrechts. Wie Schmitt schreibt:

81 Cesare Pinelli, „The Kelsen/Schmitt Controversy and the Evolving Relations between Constitutional and International Law”, Ratio Juris, 23, 2010/4, p. 495.

82 Hooker, Carl Schmitt's International Thought, op. cit., p. 49.

83 Kelsen, „Das Problem der Souveränität und die Theorie des Völkerrechtes”, op. cit., p. 447.

84 Ebd., p. 286.

85 Ders., Der soziologische und der juristische Staatsbegriff, op. cit., p. 87.

86 Ebd., p. 209. 
„[Die Großraumlehre] macht mit der geschichtlich unvermeidlich gewordenen Relativierung des Staatsbegriffes Ernst, indem sie den Begriff des Staatsgebietes entthront, [...] vermeidet es aber trotzdem, im Zuge dieser Entwicklung in ein universalistisches Weltrecht hineinzutreiben“. 87

Warum wollte aber Schmitt den Staat in der Weimarer Republik noch autoritär untermauern, in der NS-Zeit dann völkerrechtlich relativieren? Handelte es sich um eine radikale Wende im Schmittschen Lebenswerk? Mitnichten. Indem Schmitt die Souveränität infrage stellte, attackierte er freilich nicht die Souveränität des Deutschen Reiches - die er in der Weimarer Republik autoritär bestärken wollte -, sondern jene der anderen europäischen Staaten. Deswegen begrüßte Schmitt den Anti-Etatismus der nationalsozialistischen Rechtslehre als Voraussetzung für eine staatsrelativierende, weltpolitische Großraumlehre: „Mit dem Sieg der nationalsozialistischen Bewegung ist [...] auch in Deutschland [...] ein Vorstoß zur Überwindung des Staatsbegriffes im Völkerrecht erfolgreich geworden". 88 Indem Schmitt den Staatsbegriff im Völkerrecht überwand, entzog er den kleineren Staaten ihre Daseinsberechtigung. Der Souveränitätsverlust anderer Staaten geht nämlich mit dem Bedeutungszuwachs des Deutschen Reiches in Europa einher. Schmitts Weimarer Etatismus und seine NSGroßraumlehre waren insofern die zwei Seiten derselben Medaille: Einerseits die innen-, andererseits die außenpolitische Verstärkung einer einheitlich organisierten deutschen Macht. Dieser Zweck kommt besonders in seiner Reichslehre klar zum Ausdruck.

\section{5. Großraum als hegemoniale Einheit: Für das Reich}

Schmitt betrachtete also die Staatlichkeit nicht mehr als die politische Einheit, welche fähig wäre, die politischen Unterschiede in der Welt - d.h. die Welt als Pluriversum - aufrechtzuerhalten. Auch wenn Schmitt die Staaten für raumgebundene, konkrete Ordnungen erachtete, traute er ihnen aufgrund ihrer kleinen oder mittleren Größe nicht mehr zu, die Etablierung einer Welteinheit effektiv aufhalten zu können. Die Staatssouveränität war für das „europäische“ Völkerrecht konzipiert, als das Völkerrecht eigentlich die Interessen der europäischen Staaten zum Ausdruck brachte bzw. ihre Kräfteverhältnisse widerspiegelte. Was aber auf dem europäischen Kontinent noch groß oder mittelgroß war, erscheint in planetarischer Tragweite nur mittelklein und klein d.h. kein europäischer Staat wäre Schmitt zufolge imstande, sich weltpolitisch zu bewähren und sich gegen einen Weltuniversalismus zu stemmen:

„Das europäische Völkerrecht des 19. Jahrhunderts, mit seiner schwachen Mitte Europas und den westlichen Weltmächten im Hintergrunde, erscheint uns heute als eine von Riesen überschattete Kleinwelt. Dieser Horizont is für ein modern gedachtes Völkerrecht nicht mehr möglich. Wir denken heute planetarisch und in Großräumen“.89

\footnotetext{
87 Schmitt, „Raum und Großraum im Völkerrecht”, op. cit., p. 261. [Hervorhebung von mir - P.T.]

88 Ders., Völkerrechtliche Großraumordnung, op. cit. p. 55.

89 Ebd., p. 61.
} 
Als Konsequenz des vermeintlichen (inneren wie äußeren) Verfalls der staatlichen Macht schlug Schmitt neue Kategorien für das Völkerrecht vor:

\begin{abstract}
„Möglichkeit und Zukunft des Völkerrechts hängen also davon ab, daß die wirklich tragenden und gestaltenden Größen des Zusammenlebens der Völker richtig erkannt und zum Ausgangspunkt der Erörterung und Begriffsbildung gemacht werden."90
\end{abstract}

In der Großraumlehre verband Schmitt sein Grundprinzip über die Raumgebundenheit des Rechts mit dem Ziel, ein weltumfassendes Recht wirksam zu verhindern. Der Großraum erfüllte daher beide Erwartungen, welchen der souveräne Staat Schmitt zufolge nicht mehr gerecht werden könne: Der Großraum ist nämlich raumgebunden und groß genug. In diesem Zusammenhang erscheint das Reich - als das politische Zentrum eines Großraumes. Die Großraumlehre ist nämlich zugleich eine Reichslehre: Der Großraum solle sich als neue politische Einheit in der Weltordnung um ein hegemoniales Reich herum etablieren. Wie Schmitt schrieb: „Diese tragenden und gestaltenden Größen [der neuen Weltordnung] sind heute nicht mehr, wie im 18. und 19. Jahrhundert, Staaten, sondern Reiche". ${ }^{91}$ Er beschrieb die Reiche als

„die führenden und tragenden Mächte, deren politische Idee in einem bestimmten Großraum ausstrahlt und die für diesen Großraum die Interventionen fremdräumiger Mächte grundsätzlich ausschließen”.92

Ein Reich entstehe innerhalb einer Großraumordnung, „deren Garant und Hüter ein Volk ist, das sich dieser Aufgabe gewachsen zeigt".93 Als einziges universelles Prinzip bleibe ein Interventionsverbot für „raumfremde Mächte”, was die hegemoniale Position des Reiches (und seines Volkes) über die anderen Völker innerhalb eines Großraumes garantieren solle. Die Reichsidee verneint also das Gleichgewicht souveräner Staaten und die Gleichheit aller Völker - diese hegemoniale Wende setze die Abschaffung der staatlichen Souveränität voraus: Während sich einige Staaten zu Reichen entwickeln - und einen Großraum erobern -, verlieren die anderen Staaten, die im Großraum einem Reich unterstellt werden, ihre Souveränität. Der Reichsidee lag also eine hegemoniale und hierarchische Struktur zugrunde. Wie der NS-Funktionär Franz Alfred Six zusammenfasste: „Nicht der staatliche Charakter, sondern die hegemoniale Struktur bedingt die Ordnung des Reiches."94 Das Ergebnis der Schmittschen Staatsrelativierung ist also die Etablierung einer noch größeren, kraftvolleren Macht, die fähig sei, eine Welteinheit zu verhindern bzw. ihrer eigenen Herrschaft

\footnotetext{
90 Ebd., p. 51.

91 Ebd.

92 Ebd., p. 49.

93 Ebd., p. 61.

94 Franz Alfred Six, Das Reich und Europa. Eine politisch-historische Skizze, Zentralverlag der NSDAP, Berlin, 1943, p. 28.
} 
auch kleinere Staaten und Völker, die in der Nähe des Reiches existieren, zu unterwerfen: Das Reich ist eigentlich die politische Einheit eines Volkes, das um sich herum ein größeres Gebiet anschafft, wo Einmischungen anderer Reiche ausgeschlossen bleiben - was im Umkehrschluss bedeutet, dass alle anderen Völker innerhalb des Großraumes dem herrschenden Reichsvolk (als Herrenvolk) schutzlos ausgeliefert werden.

Schmitt übertrug seinen antipluralistischen Etatismus auf das Konzept des Großraumes: Die Welt solle demnach nicht mehr aus mehreren Staaten, sondern aus mehreren Großräumen bestehen. Berechtigt fragt aber Antonino Scalone, worin sich das Wesen des Großraumes von jenem des Staates eigentlich unterscheidet. 95 Auch der NS-Jurist Ernst Rudolf Huber bemängelte, dass das "Reich“ in der Schmittschen Großraumlehre eigentlich die Funktion eines "Überstaates“ oder eines „Großstaates" aufweise, insofern weiterhin einem etatistischen Denken - wenn auch auf ein größeres Gebiet bezogen - verhangen bleibe. ${ }^{96}$ Ein wesentlicher Bruch zwischen dem etatistischen und dem großräumlichen Denken lässt sich nämlich nicht erkennen, der Unterschied zwischen Reich (Großraum) und Staat ist nicht qualitativ - wie etwa die Kelsensche Unterscheidung zwischen dem Staat als „völkerrechtliche Teilrechtsordnung“ und dem Staat als souveräne Macht -, sondern nur quantitativ. Der Zweck des Staates und des Reiches ist derselbe: Beide sollten eine pluralistische Weltordnung durch Herausbildung politisch maßgebender, homogen und hegemonial strukturierter Einheiten bzw. eine homogene, antipluralistische Innenstruktur gewährleisten.

Der eigentliche Sinn der Großraum- und der Reichslehre bzw. ihr Unterschied zum Etatismus erklären sich nur aus dem historischen Kontext. Schmitt wollte in seinen Weimarer Schriften die Staatlichkeit als innenpolitisches, autoritäres Konzept gegen die pluralistische Demokratie ins Feld führen. Nach 1933 ging es aber nicht mehr um die innere Struktur des Staates, er wollte daher die externe Expansion untermauern: Die Reichsidee richtete sich dann als hegemoniales Konzept gegen die Staatlichkeit der zu erobernden Völker. Während sich sein autoritärer Etatismus auf die Stärkung des deutschen Staates bezog, zielte sein Staatsrelativismus auf die anderen europäischen Staaten. Insofern stand sein völkerrechtlicher Staatsrelativismus ebenso im Interesse des autoritären deutschen Staates.

\section{GROSSRAUMLEHRE ALS NATIONALSOZIALISTISCHE LEHRE}

Deutschland ist - wie der Anthropologe Helmut Plessner feststellte - „eine verspätete Nation", die in der Weltgeschichte auf die Weltbühne trat, als die anderen europäischen Mächte sich schon etablierten und die Welt untereinander aufteilten. ${ }^{97}$ Dem Deutschen Reich fehlte der Raum, um sich wirklich als ein Reich betrachten zu können. Das Gefühl, dass die Deutschen in der „Aufteilung“

95 Antonino Scalone, „La teoria schmittiana del grande spazio: una prospettiva post-statuale?” Scienze e Politica, 29, 2017, p. 194.

96 Ernst Rudolf Huber, „Positionen und Begriffe". Eine Auseinandersetzung mit Carl Schmitt”, Zeitschrift für die gesamte Staatswissenschaft, 101, 1941, p. 44.

97 Helmut Plessner, Die verspätete Nation. Über die politische Verführbarkeit bürgerlichen Geistes, Kohlhammer, Stuttgart, 1959, p. 11. 
der Welt zu kurz gekommen seien, prägte maßgeblich die Ziele der wilhelminischen Außenpolitik. Nach Andreas Hillgruber lässt sich daher die ganze Periode zwischen der Reichsgründung 1870/71 und dem „Untergang“ 1945 als ein einheitliches Kontinuum lesen, welches auf die „Machtbehauptung und Machterweiterung Preußens" abgezielt habe. ${ }^{98} \mathrm{Um}$ eine ähnliche Erklärung der NS-Außenpolitik bemühten sich auch nationalsozialistische Intellektuellen, die in der NS-Politik - wie etwa der NS-nahe Historiker, Otto Westphal meinte - die Vollbringung der Bismarck'schen Ziele zu erkennen glaubten. ${ }^{99}$

In diesem Kapitel wird die Großraumlehre stärker im Kontext der nationalsozialistischen Volks- und Reichstheorien verortet. (2.1.; 2.2.) Dabei wird sich auch zeigen, dass und warum Schmitts Lehre von mehreren NSTheoretikern kritisiert wurde - die Frage, ob die Schmittsche Großraumlehre wirklich eine NS-Lehre ist, lässt sich insofern nicht eindeutig beantworten. Auch wenn seine Intentionen der NS-Politik entsprachen, war Schmitt nicht von allen NS-Juristen positiv rezipiert. (2. 3.)

\section{1. Großraum und Volk}

Obgleich sich Schmitt bereits in seinen Weimarer Schriften völkisch anmutender Ideen und Begriffe bedient hatte - etwa indem er die Homogenität / Gleichartigkeit als Voraussetzung der Demokratie festmachte 100 -, deutete er seine eher dezisionistische und etatistische Rechtslehre nach 1933 im explizit völkischen Sinne um. ${ }^{101}$ In der Schmittschen Großraumlehre trennten sich aber die Großräume voneinander nicht unbedingt entlang rassisch-völkischer Gegensätze, sondern als geopolitische Einheiten, denen nicht die „biologische” Reinheit, sondern das Interventionsverbot als Grundgedanke zugrunde lag. ${ }^{102}$ Der Großraum diente bei Schmitt primär nicht der rassischen Absonderung, sondern dem Erhalt des Politischen, damit die Welt weiterhin politisch (plural) organisiert bleibe. 103

98 Andreas Hillgruber, Kontinuität und Diskontinuität in der deutschen Außenpolitik von Bismarck bis Hitler, Droste, Düsseldorf, 1969, p. 3f. 481.

99 Otto Westphal, „Bismarck und Hitler”, Vergangenheit und Gegenwart, 23, 1933/9, pp. 469-

100 Schmitt, Die geistesgeschichtliche Lage des heutigen Parlamentarismus, op. cit., pp. 13ff.; ders., Verfassungslehre, op. cit., p. 79., p. 227f., p. 234.

101 Als Anfang dieser eindeutig völkischen Phase siehe u.a. ders., Staat, Bewegung, Volk. Die Dreigliederung der politischen Einheit, Hanseatische, Hamburg, 1933.

102 Zur (in gewisser Hinsicht vereinfachenden) Unterscheidung zwischen Schmitts etatistischer Großraumlehre und den völkischen NS-Großraumlehren siehe Mathias Schmoeckel, Die Grossraumtheorie. Ein Beitrag zur Geschichte der Völkerrechtswissenschaft im Dritten Reich insbesondere der Kriegszeit, Duncker und Humblot, Berlin, 1994, pp. 174ff.

103 Daher stoß Schmitts Großraumlehre auf Kritik seitens vieler NS-Theoretiker; siehe u.a. Werner Best, „Völkische Großraumordnung”, Deutsches Recht, 10, 1940, pp. 1006f.; ders., "Nochmals: völkische Großraumordnung statt "völkerrechtliche" Großraumordnung", Deutsches Recht, 10, 1940, pp. 1533f.; Reinhard Höhn, „Großraumordnung und völkisches RechtsdenkenZugleich eine Auseinandersetzung mit der nunmehr in 3. Ausgabe vorliegenden Schritft von Carl Schmitt: "Völkerrechtliche Großraumordnung mit Interventionsverbote für raumfremde Mächte»", Reich - Volksordnung - Lebensraum, 1, 1941, pp. 256-313. 
Gleichzeitig wollte Schmitt den etatistischen Grundgedanken nicht vollkommen aufgeben. Wie schon darauf hingewiesen wurde, bestand kaum konzeptueller Unterschied zwischen Staat und Reich/Großraum. Eine qualitative Differenz hätte sich nur aus einer völkischen Begründung des Reiches (des Großraumes) ergeben - Schmitt hielt aber das staatliche Organisationsprinzip für „organisatorische[s] Minimum“ und "Grundlage“ auch bezüglich eines Reiches, weil „im bisherigen Staatsbegriff ein Mindestmaß von innerer, berechenbarer Organisation und innerer Disziplin enthalten ist". ${ }^{104}$ Er wollte die Staatlichkeit also mit der Reichsidee nicht völkisch abschaffen, sondern dialektisch aufheben, indem die Staatlichkeit zu einem größeren und mächtigeren Reich weitergedacht wurde. Die Hinweise auf die Berechenbarkeit und die Disziplin des Staatsorganisationsprinzips lassen sich allerdings nicht als Kritik am willkürlichmythischen Volksdenken verstehen, weil Schmitt die Wichtigkeit eines volksbestimmten Völkerrechtes selbst betonte. ${ }^{105}$ Er wollte das völkische Denken aber auch etatistisch - und noch mehr: großräumlich-reichlich - untermauern.

Den NS-Staatsrechtler Otto Koellreutter überzeugte aber Schmitts völkische Wende nicht. ${ }^{106}$ Er hielt Schmitt vor, nicht völkisch genug, sondern immer noch etatistisch zu denken. ${ }^{107}$ Koellreutter betonte die zentrale Bedeutung des „Volkes“ - statt des Staates - für das nationalsozialistische Rechtsdenken: „Das politische A und $\mathrm{O}$ der nationalsozialistischen Weltanschauung ist das Volk", 108 und daher „[tritt] für eine völkische Auffassung der Staat als Eigenwert in den Hintergrund". ${ }^{109}$ Er bemängelte in diesem Sinne den fehlenden völkischen Charakter der Schmittschen Rechtslehre. Koellreutter lehnte auch den Schmittschen Begriff des Politischen ab,110 weil dieser formalistisch-nihilistisch sei, insofern die "Gemeinschaftlichkeit" des Nationalsozialismus nicht mit einbeziehe. ${ }^{111}$ In seiner Kritik rückte er Schmitt sogar in die Nähe von Hans Kelsen, ${ }^{112}$ als ob beide einem formalistischen Rechtsdenken angehängt hätten daher meinte er, dass Schmitt in der Weimarer Republik dem politischen Liberalismus das Wort geredet habe. ${ }^{113}$

104 Schmitt, Völkerrechtliche Großraumordnung, op. cit., p. 56.

105 Ebd., p. 58.

$106 \mathrm{Zu}$ Koellreutters (auch persönlich motivierter) Antipathie gegenüber Schmitt siehe Jörg Schmidt, Otto Koellreutter 1883-1972. Sein Leben, sein Werk, seine Zeit, Peter Lang, Frankfurt/M et al., 1995, pp. 84ff.

107 Otto Koellreutter, Volk und Staat in der Weltanschauung des Nationalsozialismus, Pan, Berlin-Charlottenburg, 1935, p. 12.

108 Ders., Der deutsche Führerstaat, Mohr Siebeck, Tübingen, 1934, p. 8.

109 Ders., „Volk und Staat in der Verfassungskrise. Zugleich eine Auseinandersetzung mit der Verfassungslehre Carl Schmitts”, in Fritz Berber (Hg.), Zum Neubau der Verfassung, Junker und Dünnhaupt, Berlin, 1933, p. 12.

110 Ders., Volk und Staat in der Weltanschauung des Nationalsozialismus, op. cit., $8 \mathrm{ff}$. $2 \mathrm{f}$.

111 Ders., Deutsches Verfassungsrecht. Ein Grundriss, Junker und Dünhaupt, Berlin, 1938, p.

112 Ders., „Volk und Staat in der Verfassungskrise”, op. cit., p. 13.

113 Ders., Vom Sinn und Wesen der nationalen Revolution, Mohr Siebeck, Tübingen, 1933, p. 32. 
Koellreutter hob auch bezüglich der Großraumlehre hervor, dass der Raum vom Volk her zu denken sei.114 Der als "unecht” beschriebenen Schmittschen Großraumlehre stellte der NS-Wirtschaftspolitiker Werner Daitz eine „echte” Großraumlehre - eher als kurze kritische Bemerkung - gegenüber, welche die Einheit nicht als räumliche, sondern als völkisch-rassische Kategorie auffasste. ${ }^{115}$ Grund der Kritik war Schmitts Position, nach der eine neue Völkerrechtsordnung nicht nur personenbestimmter (d.h. völkischer) Abgrenzungen enthalten solle, weil eine territoriale Absonderung nicht zu ersetzen (zu überwinden) sei.116 Daitz ging es weniger um die politische Absonderung hegemonialer Strukturen, als um die rassische Abgrenzung der einzelnen „Völker“.

Der NS-Völkerrechtler Gustav Adolf Walz wies ebenso darauf hin, dass die Großraumlehre nur ein geopolitisches Konzept sei, daher nicht das politische Endziel sein solle. ${ }^{117}$ Walz meinte, dass die Großraumlehre - ähnlich zu einem „liberalen“ Staatsverständnis ${ }^{118}$ - das Volk (Staatsvolk) vom Gebiet (Staatsgebiet) her denke, was sogar zur Assimilation aller Völker, die in einem Raum leben, führen könne. ${ }^{119}$ Ähnlich wie Koellreutter oder Daitz, begnügte sich Walz mit der Idee, dass die Welt politisch plural bleibe, keinesfalls: Sie alle wollten die Welt nach rassischen Kategorien in Großräume aufteilen. Während aber Daitz ein „biologisches Interventionsverbot“, d.h. ein Mischungsverbot der Völker forderte, ${ }^{120}$ lehnte Walz ein allgemeines - egal ob geopolitisch oder rassisch formuliertes - Interventionsverbot grundsätzlich ab, er wollte hingegen „eine völkische Intervention“ als völkerrechtliche Möglichkeit für das „Urvolk“ eines Raumes etablieren:121 Es heißt: Größere Völker sollen andere Gebiete (auch von anderen Großräumen) erobern können, falls ein Teil der dortigen Bevölkerung mit ihnen „rassisch“ verwandt sei.

Dabei ist es nicht zu vergessen, dass „Europa“ in den meisten NS-Theorien mit dem "Germanentum" gleichgesetzt wurde - so gewinnt auch Daitzs Aufforderung „Europa den Europäern”122 eine rassisch-aggressive Bedeutung. Sogar die antiken Kulturen, die als Wiege Europas gelten, wurden dabei als außereuropäische, mediterrane Elemente abgelehnt. ${ }^{123}$ Franz Alfred Six definierte etwa Europa als „[den] aus der Gestaltungskraft der arischen Rasse

114 Ders., Grundriß der Allgemeinen Staatslehre, Mohr Siebeck, Tübingen, 1933, p. 27.

115 Werner Daitz, „Echte und unechte Großräume. Gesetze des Lebensraums”, Reich, Volksordnung, Lebensraum - Zeitschrift für die völkische Verfassung und Verwaltung, 2, 1942, pp. $87 \mathrm{ff}$.

116 Schmitt, Völkerrechtliche Großraumordnung, op. cit., p. 59.

117 Gustav Adolf Walz, Völkerrechtsordnung und Nationalsozialismus. Untersuchungen zur Erneuerung des Völkerrechts, Zentralverlag der NSDAP, München, 1942, pp. 131ff.

118 Ebd., pp. $86 f f$.

119 Ebd., p. 133.

120 Daitz, „Echte und unechte Großräume”, op. cit., p. 93.

121 Walz, Völkerrechtsordnung und Nationalsozialismus, op. cit., p. 116.

122 Daitz, „Echte und unechte Großräume”, op. cit., p. 88.

123 Franz Alfred Six, „Das Reich und die Grundlegung Europas”, in ders. (Hg.), Jahrbuch der Weltpolitik, Juncker und Dünnhaupt., Berlin, 1942, p. 15.. 
geschaffene[n] Lebensraum der europäischen Rassen und Völker". ${ }^{124}$ Er meinte, dass die europäische Kultur durch die "germanische Befreiung des Kontinents vom mediterranen Einflußgebiet” entstanden hätte. ${ }^{125}$ Er verortete den „Anfang“ der europäischen Geschichte beim Auftreten der "Germanen“. ${ }^{126}$ Six sprach somit der hellenischen und der römischen Kultur das „Europäische” ab. ${ }^{127}$ Mit ähnlich "germanischem" Rassismus wurde auch das Christentum aus dem wahrhaft „Europäischen” ausgeschlossen. Der NS-Theoretiker Friedrich Schmidt beschrieb etwa die christliche Religion und Kultur als ein „außerhalb der Lebenswelt der germanischen Stämme” entstandenes und daher einem „germanischen Europa“ fremdes Element. ${ }^{128}$

\section{2. Großraum und Reich}

Die Reichsidee war eigentlich eine universalistische, übervölkische Idee, ${ }^{129}$ in diesem Sinne hätte sie dem völkischen Nationalsozialismus nicht entsprochen. ${ }^{130}$ Sowohl die nationalistische als auch die etatistische Umdeutung des Reichsbegriffes lief der mittelalterlichen und (früh)neuzeitlichen Reichsidee entgegen, 131 die religiös und supranational begründet war. Daher wurde das Reich völkisch umgedeutet, als ob selbst das Heilige Römische Reich der deutschen Nation ein deutsches Reich gewesen wäre. Der NS-Jurist Ernst Rudolf Huber versuchte den völkischen Reichsbegriff sogar auf die ganze Reichsgeschichte anzuwenden, als ob das Reich schon immer „die konkrete politische Gestalt [wäre - P.T.], in der das deutsche Volk zum Staat geworden ist". ${ }^{132}$ In der NS-Rechtswissenschaft erschien das Reich entweder als ein völkerrechtliches Zukunftsprojekt (Schmitt, Daitz, Walz, Gürke) oder als ein Proto-Nationalstaat der Deutschen (Huber). Die Idee eines neuen Reiches war auch in der faschistischen Publizistik der 1920er Jahre vorhanden. ${ }^{133}$

Die Reichsidee wurde im Nationalsozialismus gleichzeitig auch als Abgrenzung zum neuzeitlichen Imperialismus aufgefasst.134 Der SSVölkerrechtler Gürke meinte etwa, dass die neue völkerrechtliche Ordnung, die

124 Ebd., p. 14.

125 Ebd., p. 16.

126 Ebd., p. 10. [Hervorgebung von mir - P.T.]

127 Ebd., p. 18.

128 Friedrich Schmidt, Das Reich als Aufgabe, Nordland, Berlin, 1940, p. 77.

129 In diesem Sinne forderte Otto von Habsburg ein europäisches Reich als supranationale Einheit für Nachkriegseuropa; vgl. Otto von Habsburg, Die Reichsidee. Geschichte und Zukunft einer übernationalen Ordnung, Amalthea, Wien / München, 1986.

130 Erkannt auch bei Gürke: Volk und Volkrecht, op. cit., p. 84.

131 Fritz Gaupp, Deutsche Fälschung der abendländischen Reichsidee, Haupt, Bern, 1946.

132 Ernst Rudolf Huber, Verfassungsrecht des Großdeutschen Reiches, Hanseatische, Hamburg, 1939, p. 167.

133 U.a. Julius Evola, Imperialismo pagano. Il fascismo dinanzi al pericolo euro-cristiano, Atanor, Roma, 1928.

134 U.a. Ulrich von Hassel, „Lebensraum oder Imperialismus”, in Joachim von Ribbentrop (Hg.), Europa. Handbuch der politischen, wirtschaftlichen und kulturellen Entwicklung des neuen Europa, Heiling, Leipzig, 1943, p. 28. 
vom NS-Deutschland angestrebt war, weder Imperialismus noch Universalismus bedeute, sondern sie schaffe „[eine] Ordnung nebeneinander bestehender Staaten zu einer Völkerrechtsgemeinschaft“. ${ }^{135}$ Daitz verstand das Deutsche Reich sogar als Form antinationalistischer Gemeinnützigkeit, als ob dem Reich kein hegemoniales Denken zugrunde läge: „So zeigt sich, daß wir auch im neuen Europa nicht mehr nationalistisch eigennützig, sondern nur noch nationalsozialistisch gemeinnützig denken dürfen". ${ }^{136}$ Es war aber auch für diese rhetorisch „anti-kolonialistischen“, „anti-imperialistischen“ NS-Theoretiker anstrebenswert, dass „[d]ie stärkste Nation [...] Führer sein [muß]”. ${ }^{137}$ Darin, wie etwa Friedrich Alfred Six das historische deutsch-römische Reich charakterisierte, lassen sich auch die Ziele der NS-Europapolitik erkennen: „Die kaiserliche Macht ist Reichsmacht, als solche eine auf der Grundlage der deutschen Herrschaft ausstrahlende universale Souveränität". ${ }^{138}$ Die "universale Souveränität" bezog sich nicht auf Europa, sondern auf die deutsche Vormachtstellung - dieser „Ausstrahlung“ hätten sich keine Nationen des Kontinents entziehen können. Wie der NS-Historiker und Mitarbeiter des Auswärtigen Amtes, Werner Frauendienst das Ziel einer deutschen Großraumund Reichspolitik zusammenfasste:

„Für das Deutschtum im europäischen Siedlungsraum deckt der Staat das Volk nicht. Es reicht weiter in Lebensgebiete anderer Völker hinein, mit dieser unlösbar verzahnt. Diese in seinem Lebens- und Wirkungsbereich eingesprengten Fremdvölker bedürfen zu ihrer Existenz der engsten Anlehnung an Großdeutschland."139

Eine wahrlich nationalsozialistische Großraumlehre zielte also nicht nur auf die völkische Absonderung - diese hätte nämlich für geschlossene Räume der einzelnen Völker geführt. Die Unterwerfung der anderen Völker hätte hingegen einen deutsch geführten, aber völkisch keinesfalls „reinen“ Großraum etabliert insofern bemühte sich die nationalsozialistische Völkerrechtslehre um eine Legitimierung eines womöglich völkisch heterogenen Großraums. Schmitt hatte es dabei leichter, seine Großraumlehre war nicht primär völkisch ausgerichtet, er konnte die Vormachtstellung des Deutschen Reiches bloß geopolitisch rechtfertigen. Die Vertreter der völkischen Großraumlehre lösten den Widerspruch mit dem Konzept des „Urvolks“ auf. Wie Walz schrieb: „Das schöpferische Urvolk erscheint in diesem System als Träger und Kern eines regional begrenzten Großraums, in dem es letztverantwortlich über die konkrete Verwirklichung seiner politischen Konzeption wacht."140 Im Europa - oder zumindest in der Mitte Europas - seien die Deutschen das „Urvolk“, dem daher

135 Gürke: Volk und Volkrecht, op. cit., p. 83.

136 Daitz, „Echte und unechte Großräume. Gesetze des Lebensraums”, op. cit., p. 89.

137 von Hassel, „Lebensraum oder Imperialismus”, op. cit., p. 32.

138 Six, Das Reich und Europa, op. cit., p. 25. [Hervorgebung von mir - P.T.]

139 Werner Frauendienst, „Der innere Neuaufbau des Reiches als Beitrag zur europäischen Ordnung”, in Six (Hg.), Jahrbuch der Weltpolitik, op. cit., p. 125.

140 Walz, Völkerrechtsordnung und Nationalsozialismus, op. cit., p. 143. [Hervorhebung von mir - P.T.] 
das völkische wie geopolitische Primat über alle anderen Völker zustehe: „Der Führungsanspruch fällt naturgemäß dem Urvolk zu, das als Schöpfer der völkischen Konzeption auf den politischen Plan getreten ist und sich als verantwortlicher Garant seiner Verwirklichung fühlt."141

Das NS-Deutschland wollte dementsprechend Europa nach den Bedürfnissen des deutschen Volkes neu organisieren. In diesem Sinne wurde ein "Germanisches Reich" angestrebt, ${ }^{142}$ das von mehreren Satellitenstaaten oder Satellitenräumen umgeben werden sollte. Das NS-Deutschland wollte somit alle Deutschen in einem Reich (wieder)vereinen bzw. die anderen europäischen Gebiete an das Reich unmittelbar oder mittelbar - als Großraum - anschließen:

\begin{abstract}
„Der Errichtung der inneren und äußeren Souveränität des Reiches folgt in schnellen Zügen der Aufbau Großdeutschlands als eines Volkreiches der Deutschen, die Wiederaufnahme der historischen Reichspolitik durch die Errichtung des Protektorats Böhmen und Mähren und schirmende Gewalt der europäischen Mitte im Bewußtsein der germanischen Welt”. ${ }^{143}$
\end{abstract}

Das Reich hätte den Mittelpunkt eines neuen Europa bilden sollen. ${ }^{144}$ Wie Walz verkündete: Das Ziel eines deutschen Großraumes sei die „rangordnungsmäßige positive Einbeziehung der kleineren, dem politischen Großkampf nicht gewachsenen Völker“. ${ }^{145}$ Bei Walz kam also dasselbe Argument vor, was auch Schmitt zu seiner Großraumlehre motivierte (1.4.): Einige Völker und Staaten seien zu klein, um eine universalistische Weltordnung verhindern zu können - sie sollen sich daher den Großräumen der größeren Völker fügen.

Die Idee, Europa nationalsozialistisch / faschistisch zu vereinen, wurde auch in anderen europäischen Ländern unter gewissen - meist NS-freundlichen Intellektuellenkreisen hochgetragen. Sie verstanden sich zwar als „Europäer”, aber erhofften sich die Einheit Europas von der deutschen Macht. ${ }^{146}$ Besonders nach dem Überfall der Sowjetunion durch das Dritte Reich verstärkte sich der „eurofaschistische“ Gedanke, dass Europa als „Bollwerk" gegen den „Bolschewismus“ zu schützen sei. ${ }^{147}$ Als ein Beispiel eines „eurofaschistischen“ Denkers kann hier etwa der französische Essayist und NS-Kollaborateur, Pierre Drieu la Rochelle kurz erwähnt werden. Er meinte, dass die europäische Einheit

\footnotetext{
141 Ebd., p. 141.

142 Salowski, „Europa: Idee und Wirklichkeit in der nationalsozialistischen Weltanschauung und politischen Praxis”, op. cit., pp. 88f.

143 Six, Das Reich und Europa, op. cit., p. 79.

144 Schmidt, Das Reich als Aufgabe, op. cit., p. 22.

145 Walz, Völkerrechtsordnung und Nationalsozialismus, op. cit., p. 143.

146 Bernard Bruneteau, "L'Europe nouvelle" de Hitler. Une illusion des intellectuels de la France de Vichy, Rocher, Monaco, 2003, pp. $40 \mathrm{ff}$.

147 Hans Werner Neulen, Eurofaschismus und der Zweite Weltkrieg. Europas verratene Söhne, Universitas, München, 1980, p. 17.
} 
nur durch eine hegemoniale Macht zu verwirklichen sei. ${ }^{148}$ Er plädierte dabei für eine deutsche Hegemonie in Europa, weil es besser sei, von einer europäischen Macht beherrscht zu werden als von nicht-europäischen Mächten. ${ }^{149} \mathrm{Er}$ verurteilte deswegen die Angst seiner compatriot(e)s vor einem deutschen Europa. ${ }^{150}$

Großraum Europa: Großdeutsches Reich und sein Großraum ${ }^{151}$

\begin{tabular}{|c|c|c|c|}
\hline $\begin{array}{l}\text { Großdeutsc } \\
\text { (Deutschland, Österreich, Böh } \\
\text { Luxemburg, Frankreich, Elsas } \\
\text { Teile des Balkans, westlich }\end{array}$ & $\begin{array}{l}\text { s Reich } \\
\text { n, Mähren, Polen, Belgien, } \\
\text { Lothringen, Griechenland, } \\
\text { Teile der Sowjetunion) }\end{array}$ & $\begin{array}{r}\text { It } \\
\text { (Italien, Teile des } \\
\text { Mitteln }\end{array}$ & $\begin{array}{l}\text { ien } \\
\text { riaraums, östlicher } \\
\text { erraum) }\end{array}$ \\
\hline $\begin{array}{c}\text { Satellitenstaaten } \\
\text { (Slowakei, Dänemark, } \\
\text { Norwegen, Kroatien, Burgund) }\end{array}$ & $\begin{array}{c}\text { alliierte Staaten } \\
\text { (Finnland, Ungarn, } \\
\text { Rumänien, Irland, } \\
\text { Holland, Großbritannien) }\end{array}$ & $\begin{array}{c}\text { Ergänzungsraum } \\
\text { (östliche Teile der } \\
\text { Sowjetunion, Afrika) }\end{array}$ & $\begin{array}{c}\text { unabhängige Staaten } \\
\text { (Spanien, Portugal, } \\
\text { Schweden) }\end{array}$ \\
\hline
\end{tabular}

\section{3. Schmitts Großraumlehre als NS-Lehre?}

Schmitts Großraumlehre lässt sich - trotz der Kritik, die sie schon damals erfuhr - durchaus im Kontext der NS-Kriegs- und Eroberungspolitik verorten. Auch in der theoretischen Analyse (I.) wurde aufgezeigt, dass Schmitt mit seinen Büchern, Aufsätzen immer auch politische Ziele verfolgte. Der eigentliche Zweck der Großraumlehre erklärt sich insofern nicht (bloß) wissenschaftlich, sondern auch aus dem historischen Kontext, in dem Schmitt sie ausarbeitete. ${ }^{152}$ Es ist kein Zufall, dass er die Überwindung der souveränen Staatlichkeit bzw. die Etablierung neuer politischen Großräume in einer Zeit propagierte, als die bestehende staatliche Ordnung in Europa einer deutschen Eroberungspolitik im Wege stand.

Schmitts Idee vom Übergang des souveränen Staates in ein großräumliches Reich korrespondierte dem nationalsozialistischen Ziel, die souveränen Staaten in Europa einer deutschen Herrschaft zu unterwerfen. Der Grund, warum Schmitt nicht mehr den Staat, sondern das Reich in den Vordergrund rückte, ergibt sich also aus diesem historischen Umfeld. In der Weimarer Zeit zielten Schmitts Theorien noch auf die Dekonstruktion des liberalen Rechtsstaates bzw. die Legitimierung eines autoritären Führerstaates. Das Ziel, den liberalen Rechtsstaat zu überwinden, wurde mit dem Sieg des NS-Regimes 1933 vollzogen. Nachdem das Ende einer pluralistischen Demokratie im Deutschen Reich erreicht

148 Pierre Drieu la Rochelle, „Le problème vital de l'Europe. Ni New York, ni Moscou”, in ders.: Textes politiques 1919-1945. Présentation de Julien Hervier. Edition établie et annotée par JeanBaptiste Bruneau, Krisis, Paris, 2009, pp. 104f.

149 Ders., „L'Europe aux "extra-européens"”, in: ders., Textes politiques, op. cit., p. 383.

150 Ebd., p. 384.

151 Zusammengestellt nach Birgit Kletzin, Europa aus Rasse und Raum. Die nationalsozialistische Idee der Neuen Ordnung, LIT, Münster et al., 2000, p. 25f.

152 Diemut Majer, Nationalsozialismus im Lichte der Juristischen Zeitgeschichte. Ideologie - Staat - Besatzungsregime in Europa 1939-1945, Nomos, Baden-Baden, 2002, pp. $147 \mathrm{ff}$. 
wurde, konnte sich Schmitt der Frage annehmen, wie sich das neue Deutsche Reich für den Erhalt des weltpolitischen Pluralismus einbringen könnte. Die Großraumlehre beschrieb insofern den zweiten, nächsten Schritt der NS-Politik: Nach der Eliminierung der inneren Feinde war die Eroberung Europas auf der Tagesordnung. ${ }^{153}$ Wie Dan Diner darauf hinweist: „Diese Innovation [die Großraumlehre - P.T.] steht ohne Zweifel im Zusammenhang mit der zwei Wochen zuvor erfolgten Besetzung der Tschechoslowakei". ${ }^{154}$ Schmitt selbst stellte seine Lehre in den Dienst eines Deutschen Reiches, das Teile von Europa beherrschen bzw. fremde externe Mächte wie auch fremde innere Völker ausschließen solle:

\begin{abstract}
„Der Gedanke eines zu den Trägern und Gestaltern eines neuen Völkerrechts gehörenden Deutschen Reiches wäre früher ein utopischer Traum und das auf ihm aufgebaute Völkerrecht nur ein leeres Wunschrecht gewesen. Heute aber ist ein machtvolles Deutsches Reich entstanden. Aus einer schwachen und ohnmächtigen ist eine starke und unangreifbare Mitte Europas geworden, die imstande ist, [...] eine Ausstrahlung in den mittel- und osteuropäischen Raum hinein zu verschaffen und Einmischungen raumfremder und unvölkischer Mächte zurückzuweisen."155
\end{abstract}

Indem Schmitt Europa als einen geschlossenen Großraum konzipierte, lieferte er der NS-Propaganda ein wissenschaftlich getarntes Argument, warum das Deutsche Reich alle anderen Mächte - in concreto die USA und die Sowjetunion - aus Europa fernhalten könne. In diesem kriegspropagandistischen Sinne forderte Schmitt auch eine europäische Monroe-Doktorin - nach dem Vorbild der US-amerikanischen Monroe-Doktrin. Lothar Gruchmann beweist aber, dass Schmitt die US-amerikanische Monroe-Doktrin missverstanden habe: Die amerikanische Monroe-Doktrin war defensiver Natur, ${ }^{156}$ sie bedrohte die Unabhängigkeit der einzelnen Länder auf dem amerikanischen Kontinent nicht. ${ }^{157}$ Die deutsche „Monroe-Doktrin” zielte dagegen nicht auf die Verteidigung der europäischen Staaten, sondern auf ihre Eroberung. ${ }^{158}$

George Schwab nimmt dennoch die Großraumlehre in gewisser Hinsicht in Schutz, als ob nur eine zeitliche, aber keine inhaltliche Nähe zwischen Schmitts Großraum- und Hitlers Lebensraumkonzept bestanden hätte. ${ }^{159}$ Für Gerardo Tripolone liefere schon die Tatsache, dass Schmitt sein Konzept nicht als Lebens-

153 Carmelo Jiménez Segado, „Carl Schmitt y el derecho internacional del Reich”, Revista de Estudios Politicos, 127, 2005, p. 323f., p. 327.

154 Dan Diner, „Rassistisches Völkerrecht. Elemente einer nationalsozialistischen Weltordnung”, Vierteljahreshefte für Zeitgeschichte, 37, 1989/1, p. 49.

155 Schmitt, Völkerrechtliche Großraumordnung, op. cit., p. 63.

156 Lothar Gruchmann, Nationalsozialistische Grossraumordnung. Die Konstruktion einer "deutschen Monroe-Doktrin", DVA, Stuttgart, 1962, p. 30.

157 Ebd., p. 32.

158 Ebd., pp. 50f.

159 George Schwab, „Contextualising Carl Schmitt's Concept of Grossraum”, History of European Ideas, 19, 1994, pp. 188f. 
, sondern als Großraum bezeichnete - obwohl der Begriff des Lebensraumes besser der nationalsozialistischen Ideologie entsprochen hätte -, einen Beweis für Schmitts Distanz gegenüber dem NS-Regime. ${ }^{160} \mathrm{Im}$ Gegensatz dazu bestreitet auch Martti Koskenniemi nicht - obgleich er sich in seiner kritischen Völkerrechtslehre oft positiv auf Schmitt bezieht -, dass Schmitt seine Lehre durchaus als wissenschaftliche Begründung der damaligen Hitlerschen Außenpolitik, deren imperiale Ziele bereits 1939 unverkennbar waren, verfasste. ${ }^{161}$

Die Debatte, die über das NS-Engagement Schmitts immer noch heftig geführt wird, sei hier dahin gestellt. ${ }^{162}$ Fakt ist, dass Carl Schmitt 1936 in einer SS-Zeitung scharf angegriffen wurde ${ }^{163}$ und danach aus dem öffentlichen Leben bis auf seine Professur in Berlin und seine Position als preußischer Staatsrat zurückziehen musste. Von einer anti-nationalsozialistischen Kehrtwende kann aber keine Rede sein. ${ }^{164}$ Er verfasste die Großraumlehre schon nach seinem vermeintlichen „Rückzug”, d.h. Schmitt brach intellektuell auch nach 1936 mit dem Nationalsozialismus nicht. Nach dem Zweiten Weltkrieg versuchte er allerdings die Bedeutung seiner Lehre zu relativieren: Er behauptete, dass er „Abstand zu jeder politischen Festlegung und zu jedem Regime [nahm] gerade auch mit Bezug auf das Raum- und Großraumproblem”. ${ }^{165}$ Er beteuerte etwa, wie „gering" die Auflage und die Wirkung seiner Großraumlehre während der NS-Zeit gewesen wäre166 bzw. dass „Hitler nicht Großraumpolitik dieser Theorie, sondern eine geist- und prinzipienfeindliche Eroberungspolitik betrieben [hatte]". ${ }^{167}$ Diese Aussagen stammen aus den Jahren, als Schmitt nach dem Krieg in Nürnberg als Zeuge verhaftet war und auf eine mögliche Freilassung hoffte. ${ }^{168}$ Die Worte sind daher als Selbstschutz zu lesen, sie entsprechen nicht unbedingt einer historischen Wahrheit.

Die Gründe dafür, warum Schmitt seine Großraumlehre entwickelte, liegen aber nicht nur etwa in einem opportunistischen Anbiederungsversuch. Schmitts NS-Engagement stellt nicht nur ein historisches Detail dar, das biographischarchivarisch zu entschlüsseln sei, als ob es ansonsten ein Bruch zwischen seinen Weimarer und NS-Schriften bestanden hätte. ${ }^{169}$ Die Kontinuität zwischen Schmitt der Weimarer Zeit und dem der NS-Zeit ist auch in seinen Werken

160 Tripolone, „La doctrina de Carl Schmitt sobre el derecho internacional”, op. cit., p. 355.

161 Martti Koskenniemi, „Letter in Response to Michael Salter's Recent Paper on Carl Schmitt's Grossraum”, Chinese Journal of International Law, 12, 2013, pp. $201 \mathrm{f}$.

162 Als Erklärungen, warum sich der konservative Schmitt 1933 dem Nationalsozialismus anschloss, listet Reinhard Mehring 42 mögliche Antworten auf; eine voreilige Verurteilung Schmitts als überzeugter NS-Theoretiker scheint er abzulehnen; Reinhard Mehring, Carl Schmitt. Aufstieg und Fall, Beck, München, 2009, pp. $311 \mathrm{f}$.

163 Anonym, „Es wird immer noch peinlicher!”, Das Schwarze Korps, 10. 12. 1936, p. 2.

164 Jean-François Kervégan, Que faire de Carl Schmitt? Gallimard, Paris, 2011, pp. 36ff.

165 Carl Schmitt, „Antwort an Kempner”, in: ders., Staat, Großraum, Nomos, op. cit., p. 453.

166 Ebd., p. 456.

167 Ebd., p. 462.

168 Über diese Zeit siehe Mehring, Carl Schmitt, op. cit., pp. $442 \mathrm{ff}$.

169 William E. Scheuerman, „After Legal Determinacy: Carl Schmitt and the National Socialist Legal Order”, Cardozo Law Review, 19, 1998/5, p. 1744. 
nachzuzeichnen: Seine NS-Schriften differierten nicht von seinen früheren Hauptthesen. Die Großraumlehre von Carl Schmitt bettet sich gedanklich ebenso vollkommen in das ganze Schmittsche OEuvre ein;170 sie lässt sich als Weiterführung von seinem Begriff des Politischen, seinem antipluralistischen Etatismus bzw. seinem konkret-situativen Rechtsverständnis verstehen ${ }^{171}$ - das historische Kontext erklärt „bloß“, warum sich Schmitt gerade in der NS-Zeit dem Völkerrecht zuwandte. Als Jurist in einem hegemonialen, auf Eroberungspolitik ausgerichteten Reich, dessen (welt)politische Ziele er vollkommen teilte, setzte er sich nicht mehr mit den Fragen des Staats- und Verfassungsrechts - diese wurden nämlich von der NS-Machtübernahme im Sinne von Schmitt „gelöst“172 -, sondern dem Völkerrecht auseinander. Insofern war die Großraumlehre eine bloße Fortsetzung der Schmittschen antipluralistischen und antiuniversalistischen Rechtslehre mit anderen Mitteln.

\section{AUSBLICK: WER SOLL NOCH SCHMITT LESEN?}

In diesem Aufsatz wurde angestrebt, Schmitts Großraumlehre - auch im Kontext einiger anderen NS-Völkerrechts- und Europalehren - zu analysieren. Dabei stand u.a. die Frage im Vordergrund, warum Schmitt eine neue, poststaatliche politische Einheit begründen wollte bzw. warum er sich dem Völkerrecht erst in der NS-Zeit intensiv zuwandte. Die erste Frage lässt sich aufgrund seiner Rechtslehre beantworten: Schmitt verstand die Staatlichkeit als eine politische Einheit, welche die Etablierung einer einheitlichen (kriegsfreien) Weltordnung verhindere. Aber er erkannte die historische Relativität der Staatlichkeit, die deswegen angesichts neuer weltpolitischen Konstellation von einem anderen Konzept der politischen Einheit ersetzt werden solle, welche den Weltpluralismus effektiver gewähren könne. Die Antwort auf die zweite Frage d.h. warum Schmitt gerade in der NS-Zeit zu diesen Erkenntnissen gelang - kann uns daran erinnern, dass er mit seiner Großraumlehre nicht rein theoretisch die Weltpolitik analysieren, sondern dem kriegerischen Deutschen Reich dienlich sein wollte. Schmitt verfasste seine Theorie als ein deutscher Nationalist, der bis zum Kriegsende auf einen NS-Sieg hoffte. ${ }^{173}$

Schmitts Großraumlehre ist jedenfalls - im Gegensatz zu den Theorien der NS-Europapläne (II.) - mehr als ein bloßes Dokument der NS-Zeit, ${ }^{174}$ das nur mit archivarischem Interesse angefasst werden darf. Martti Koskenniemi hat in gewisser Hinsicht Recht, wenn er schreibt: „[T]hough it undoubtedly served German foreign policy goals, its content was independent of them." 175 Oder

170 Ryan Mitchell, „Hegemony in a Multipolar World Order: Global Constitutionalism and the Großraum”, Jus Cogens, 1, 2019/2, p. 132.

171 Teschke, „Fatal attraction”, op. cit., pp. $182 \mathrm{f}$.

172 Carl Schmitt, Reichsstatthaltergesetz, Heyman, Berlin, 1933, p. 3.; ders., Staatsgefüge und Zusammenbruck des zweiten Reiches, Hanseatische, Hamburg, 1934, p. 49.

173 Carty, „Carl Schmitt's Critique of Liberal International Legal Order”, op. cit., p. 62.

174 Zur pauschalen These, dass Schmitt nur als zeithistorisches Dokument gelesen (oder besser gesagt: nicht gelesen) werden sollte, siehe Charles Yves Zarka, „Présentation: Carl Schmitt, le nazi”, Cités, 14, 2003, pp. 161-163.; ders., „Carl Schmitt, l'ennemi substantiel et la législation nazie”, Droits, 40, 2004, pp. 173-188.

175 Koskenniemi, The Gentle Civilizer of Nations, op. cit., p. 421. 
besser gesagt: Der Inhalt ist zwar nicht frei von den NS-Zielen, aber er kann davon losgelöst gelesen werden. Schmitt nahm bezüglich der unipolaren Weltordnung anti-globalistische Kritikpunkte sowie bezüglich der souveränen Staatlichkeit post-nationalstaatliche Ansätze gegenwärtiger (meist linker) Autoren vorweg. ${ }^{176}$ Hier kann ich nur drei Aspekte, Phänomene kurz erwähnen - ohne sie näher ausführen zu wollen -, die Schmitts Aktualität und Anziehungskraft erklären können. ${ }^{177}$

Zum einen kann der Verdienst Schmitt zugerechnet werden, reale Vorgänge in der Weltpolitik - etwa die Machtverschiebungen zugunsten einiger größeren Staaten - erkannt und theoretisch reflektiert zu haben. ${ }^{178}$ Schmitt holte also den Raum- und Machtaspekt in das Völkerrecht zurück. Im Gegensatz zu Kelsen, der einer naiven Vorstellung eines friedensstiftenden, abstrakten, einheitlichen, nicht-hegemonialen „Weltrechts“ anhing, analysierte Schmitt das Völkerrecht als eine hegemoniale Struktur konkurrierender Regionalblöcke. Die tatsächliche Entwicklung des Völkerrechts (und besonders der Weltpolitik) gab den Schmittschen (und nicht den Kelsenschen) Prognosen Recht: Es entstanden regionale Großmächte (USA, Deutschland, Russland, Türkei, China, Australien usw.), deren Einfluss sich auf andere Staaten in ihrer Nachbarschaft ausstrahlt. ${ }^{179}$

Zum zweiten bietet sich Schmitts realistische Beschreibung auch als Kritik an einer (möglichen oder bestehenden) unipolaren Weltordnung an. ${ }^{180}$ Die alterglobalistischen Idee, dass das Ende der westfälischen Staatsordnung zur Weltanarchie ${ }^{181}$ bzw. zur Etablierung (national)staatlich nicht mehr kontrollierbarer, versteckten Hegemoniestrukturen ${ }^{182}$ führe, zeugt ebenso vom Schmittschen Einfluss. Ryan Mitchell schrieb sogar vom „Third World-ism of

176 Die linke Theorie versucht, Schmitt „gegen Schmitt“ zu lesen; zur kritischen Rekonstruktion dieser Position siehe u.a. Guillermo Andrés Duque Silva, „Con Schmitt y contra Schmitt: Crítica a la politica adversarial de Chantal Mouffe”, in: Delfin Ignacio Grueso (Hg.), Reconocimiento \& Democracia desafios de la Justicia. Reflexiones critico-teóricas contemporáneas, Editorial Universidad del Vale, Cali, 2015, pp. 201-220.

177 Als eine (allzu) sehr positive Rezeption von Schmitt völkerrechtlichen Ideen siehe u.a. Michael Salter, „Law, Power and International Politics with Special Reference to East Asia: Carl Schmitt's Grossraum Analysis”, Chinese Journal of International Law, 11, 2012, pp. $421 \mathrm{ff}$.

178 Horst Dreier, „Wirtschaftsraum - Großraum - Lebensraum. Facetten eines belasteten Begriffs", in ders. et al. (Hg.), Raum und Recht. FS 600 Jahre Würzburger Juristenfakultät, Duncker und Humblot, Berlin, 2002, p. 69.

179 Mitchell, „Hegemony in a Multipolar World Order”, op. cit., p. 138.; bezüglich von China siehe u.a. Salter, „Law, Power and International Politics”, pp. 404ff.

180 Deswegen dient Schmitt als Referenzautor auch für eine alterglobalistische Völkerrechtskritik; als Beispiel dazu siehe u.a. Chantal Mouffe, „Schmitt's vision of a multipolar world order”, South Atlantic Quarterly, 104, 2005/2, pp. 245-251.; zu dieser linken SchmittLesart kritisch u.a. David Chandler, "The Revival of Carl Schmitt in International Relations: The Last Refuge of Critical Theorists?”, Millenium: Journal of International Studies, 37, 2008/1, pp. 27-48.

181 U.a. Hedley Bull, The Anarchical Society. A Study of Order in World Politics, Columbia UP, New York, 1977; Alessandro Colombo, "La società anarchica tra continuità e crisi. La scuola inglese e le istituzioni internazionali”, Rassegna Italiana di Sociologia, 44, 2003/2, pp. 237-255.

182 U.a. Michael Hardt / Antonio Negri, Empire, Harvard UP, Cambridge MA, 2000, pp. 15ff. et passim. 
Schmitt“. ${ }^{183}$ Auf der anderen Seite desselben antiglobalistischen "Lagers“ bedient sich die antiuniversalistische Rechte ebenso der Schmittschen Theoreme - sie kann dabei auch den rassischen Impetus beibehalten. ${ }^{184}$ Das völkische Element des Schmittschen Denkens wird besonders in der französischen „Nouvelle Droite“ um Alain de Benoist weitergeführt. ${ }^{185}$ Benoist propagiert nämlich - ganz im Sinne von Carl Schmitt - eine Welt, in der die einzelnen Völker - womöglich um eine regionale Supermacht herum - voneinander getrennt leben (Ethnopluralismus) bzw. in der sich Europa als ein Gegenpol zu den USA etablieren solle. ${ }^{186}$ Die neurechten und die linken kritischen Theorien stimmen in ihrer antiliberalen Aversion - und in concreto: in ihrer Ablehnung gegenüber einer angelsächsisch/US-amerikanisch dominierten Weltordnung - überein. ${ }^{187}$

Zum dritten lässt sich mit Schmitt auch die Europäische Union in ihren politischen Realitäten und Möglichkeiten analysieren. ${ }^{188}$ Mit Kelsen kann nämlich nicht die Realität, sondern ein mögliches Ideal der Europäischen Union als supranationale Rechtgemeinschaft erfasst werden, als ob die EU bloß auf rechtlichen Grundlagen (ungeachtet der politischen, sozialen, ökonomischen, kulturellen usw. Gegebenheiten und Differenzen) entstehen könnte. ${ }^{189}$ Die Schmittschen Theorien holen hingegen die Raum- und Machtaspekte womöglich mit kritischem Potential - auch in den europapolitischen und rechtlichen Debatten zurück. Als Beispiel möglicher Themenfelder sei hier die Frage einer „deutschen Hegemonie“ erwähnt, 190 welche sich in Europa vor allem wirtschaftlich manifestiert.

183 Mitchell, „Hegemony in a Multipolar World Order”, op. cit., p. 131.

184 Dabei ist aber nicht zu vergessen, dass auch die antikolonialistische Linke in gewisser Hinsicht einem essentialistischen-rassischen Denken verhangen bleibt; vgl. Pierre-André Taguieff, L'imposture décoloniale. Science imaginaire et pseudo-antiracisme, Observatoire, Paris, 2020.

185 Alain de Benoist, Carl Schmitt actuel. Guerre juste, terrorisme, état d'urgence, Nomos de la Terre, Krisis, Paris, 2007.

186 Siehe u.a. ders., Europe, Tiers monde, même combat, Laffont, Paris, 1986.

187 Diese Übereinstimmung erklärt, warum die neulinke US-amerikanische Zeitschrift „Telos” inzwischen auch zum Forum neurechter Denker/innen werden konnte.

${ }_{188} \mathrm{Zu}$ einer EU-Analyse aus Schmittscher Perspektive siehe u.a. Christian Joerges, „Europe as Großraum? Shifting legal conceptualisations of the integration project”, in: ders. / Ghaleigh (Hg.), Darker Legacies of Law in Europe, op. cit., pp. 186ff.; Massimo Fichera, "Schmitt and the New World Order: A View from Europe”, Helsinki Legal Studies Research Paper, 2013, No. 26, pp. 16ff. (Zur Idee, die Europäische Union als Reich - wenn auch nicht im Schmittschen Sinne - zu denken, siehe u.a. Jan Zielonka, Europe as Empire. The Nature of the Enlarged European Union, Oxford UP, Oxford, 2007.)

$189 \mathrm{Zu}$ einer Kelsenschen Begründung der Europäischen Union siehe u.a. Jürgen Busch / Tamara Ehs, „Nachwort: EUropa als Rechtsgemeinschaft”, in: dies., Hans Kelsen und die Europäische Union. Erörterungen moderner (Nicht-)Staatlichkeit, Nomos, Baden-Baden, 2008, pp. 95-109.

$190 \mathrm{Zu}$ unterschiedlichen Aspekten einer (vermeintlichen) deutschen Hegemonie in der EU siehe u.a. William E. Peterson, "The Reluctant Hegemon? Germany Moves Center Stage in the European Union”, Journal of Common Market Studies, 49, 2011, pp. 57-75.; Christoph Schönberger, „Hegemon wider Willen. Zur Stellung Deutschlands in der Europäischen Union”, Merkur, 2012/1, pp. 1-8.; Paolo Savona, Lettera agli amici tedeschi e italiani. Come funziona il meccanismo economico europeo, Il Mio Libro, Roma, 2012; Simon Bulmer, „Germany and the Eurozone Crisis: Between Hegemony and Domestic Politics”, West European Politics, 37, 2014/6, pp. 1250ff.; Ubaldo VillaniLubelli, „Il ritorno della questione tedesca: l'inevitabile egemonia della Germania in Europa”, Rivista 
Die Großraumlehre entstand im Hintergrund der NS-Eroberungspolitik Fragen und Aspekte, die sie dabei angeschnitten hatte, verschwanden allerdings nicht mit dem „Untergang“ des Deutschen Reiches. „C.S. bleibt solange aktuell, wie die Konstellation aktuell bleibt, auf die sein Werk bezogen ist". ${ }^{191}$ Es ist aber dabei zu beachten, dass Autor/innen, die positiv auf Schmitt Bezug nehmen, oft den gleichen „Feind“ vor Augen haben wie der Nationalsozialismus: Eine universalistische Weltordnung unter dem Primat des Völkerrechts. Schmitts Großraumlehre bleibt in diesem Sinne besonders für diejenigen „aktuell“, die sich immer noch in der „Konstellation“ wähnen, angesichts derer Schmitt sein Werk verfasste - d.h. im Kampf gegen abstrakten Universalismus und eine USamerikanische „Hegemonie“.

Enviado el (Submission Date): 07/02/2021

Aceptado el (Acceptance Date): 16/04/2021

di Studi Politici Internazionali, 83, 2016/2, pp. 212ff.; Paolo Savona, La rivoluzione democratica di Heine e la Costituzione per la pace perpetua di Kant. Una seconda lettera agli amici tedeschi, Rubettino, Soveria Mannelli, 2017; Armin von Bogdandy, „German Legal Hegemony?”, MPIL Research Paper Series No. 2020-43, pp. 2-4.

191 Günther Rohrmoser, „Der Hegelsche Staat ist tot»”, Schmittiana, 6, 1998, p. 154. 